\title{
Summer temperature in the eastern part of southern South America: its variability in the twentieth century and a teleconnection with Oceania
}

\author{
Martín Jacques-Coper • Stefan Brönnimann
}

Received: 13 June 2013/Accepted: 24 December 2013/Published online: 17 January 2014

(c) Springer-Verlag Berlin Heidelberg 2014

\begin{abstract}
The 1907-2001 summer-to-summer surface air temperature variability in the eastern part of southern South America (SSA, partly including Patagonia) is analysed. Based on records from instruments located next to the Atlantic Ocean $\left(36^{\circ} \mathrm{S}-55^{\circ} \mathrm{S}\right)$, we define indices for the interannual and interdecadal timescales. The main interdecadal mode reflects the late-1970s cold-to-warm climate shift in the region and a warm-to-cold transition during early 1930s. Although it has been in phase with the Pacific Decadal Oscillation (PDO) index since the 1960s, they diverged in the preceding decades. The main interannual variability index exhibits high spectral power at $\sim 3.4$ years and is representative of temperature variability in a broad area in the southern half of the continent. Eleven-years running correlation coefficients between this index and December-to-February (DJF) Niño3.4 show significant decadal fluctuations, out-of-phase with the running correlation with a DJF index of the Southern Annular Mode. The main interannual variability index is associated with a barotropic wavetrain-like pattern extending over the South Pacific from Oceania to SSA. During warm (cold) summers in SSA, significant anticyclonic (cyclonic) anomalies tend to predominate over eastern Australia, to the north of the Ross Sea, and to the east of SSA, whereas anomalous cyclonic (anticyclonic) circulation is observed over New Zealand and west of SSA. This teleconnection links warm (cold) SSA anomalies with dry (wet) summers in eastern Australia. The covariability seems to be influenced by the characteristics of tropical
\end{abstract}

M. Jacques-Coper $(\bowtie) \cdot S$. Brönnimann

Oeschger Centre for Climate Change Research and Institute

of Geography, University of Bern, Hallerstrasse 12,

3012 Bern, Switzerland

e-mail: jacques@giub.unibe.ch forcing; indeed, a disruption has been observed since late 1970s, presumably due to the PDO warm phase.

Keywords Interannual variability $\cdot$ Interdecadal variability $\cdot$ South America $\cdot$ Patagonia $\cdot$ Oceania . Teleconnection

\section{Introduction}

South America (SA), the largest land mass south of the equator, is a key region for the study of climate processes and dynamics in the southern hemisphere (SH) (Luterbacher et al. 2011). The continent comprises diverse climatological regions, in part due to its meridional extent and prominent orography (Garreaud et al. 2008). However, a relatively dense network of surface and upper-air instrumental observations over SA is characteristic only of the second half of the twentieth century (Garreaud et al. 2008). Thus, much research on climate processes in SA has been confined to the second half of the twentieth century. Similarly, the scarce availability of long-term highly-resolved proxies limits reliable climate reconstruction from interannual to interdecadal timescales (Neukom et al. 2011).

As a result, the assessment of interannual and interdecadal climate variability in southern South America (SSA), which is our first research motivation, has been restricted due to data availability. Despite this fact, some papers have dealt with multidecadal climate changes in SSA. Neukom et al. $(2010,2011)$ reconstructed by means of local and remote predictors both surface air temperature (SAT) and precipitation for summer over the last centuries for this region, reaching $\mathrm{AD} 900$ and $\mathrm{AD}$ 1498, respectively. Considering this multi-centennial period, they found a moistening trend into the twentieth century, whereas 
summer temperatures were found to be comparable to earlier warm periods.

The internal heterogeneity of SSA is stressed by papers focusing on recent climate mechanisms and trends of this region. Based on instrumental records, Rosenblüth et al. (1997) found local warming rates between 1.3 and $2{ }^{\circ} \mathrm{C}$ per century (but twice as large in the last three decades analysed) over SSA for 1933-1992 and also a cooling trend from the $1950 \mathrm{~s}$ to the $1970 \mathrm{~s}$ around $41^{\circ} \mathrm{S}$, which was mostly influenced by minimum temperature changes. Besides, in particular during summer, local 1960-1992 trends showed large regional differences within SSA.

Particularly, as described by Garreaud et al. (2012), the southern part of SSA, Patagonia $\left(40^{\circ} \mathrm{S}-55^{\circ} \mathrm{S}\right)$, is a diverse region: the southern Andes are a natural limit between its narrow western part, which presents a temperate and hyperhumid climate and the broad arid plains of eastern Patagonia, with windy and evaporative conditions at the surface, and a thermal amplitude between summer and winter of more than $10^{\circ} \mathrm{C}$. Moreover, during the last 40 years, a drying trend west of the Andes and a subtle precipitation increase in the southern tip of the continent have been observed.

Eastern SSA exhibited a very pronounced and abrupt DJF SAT increase in late 1970s, embedded in a continentwide climate shift (Jacques 2009). This large-scale event, whose origin is still not well understood, was firstly referred to as a North Pacific shift (Trenberth 1990) and its manifestations in the northern hemisphere have been well described. However, previous research on multidecadal regimes and regime changes leaves some questions unanswered. Is it possible to detect a previous rapid summertime climate shift in SSA in the twentieth century, before the late 1970s? Are there any other evidences in instrumental records from SSA that could allow us to speak of a shifty climate (Kerr 1992) there?

In the context of global warming, eastern SSA (and in general, the southern half of SA) is also a very particular region: after the abrupt DJF SAT increase in the late 1970s, it showed almost neutral and even negative SAT trends during the last decades of the twentieth century, a feature that is even more pronounced during summer (Falvey and Garreaud 2009; Trenberth et al. 2007). Moreover, at a global scale, IPCC multi-model mean projections of SAT for the twenty-first century (Meehl et al. 2007) show a nonuniform spatial pattern, with SSA being one of the regions with minimum warming over land considering various scenarios and time periods.

All previous results motivate a specific research in eastern Patagonia with a focus on summer and the exploration of possible relationships of this region with other areas of SA and the SH. For this, we aim to extend the analysis to the whole of the twentieth century and consider the interannual and interdecadal timescales separately.

Our second research motivation deals with the stability of the effects of various climate modes at different timescales: mainly ENSO, the Southern Annular Mode (SAM, also known as the Antarctic Oscillation, AAO), and the Pacific Decadal Oscillation (PDO). Although their spatial patterns have been thoroughly examined and well established (Garreaud et al. 2008), the relatively short length of available local climate time series hinders the in-depth exploration of possible instabilities of their effects and thus limits our understanding of natural and anthropogenic processes that may be crucial in the context of climate change. While ENSO does not have a strong impact on SAT there (Aceituno 1988), SAM seems to have a clear imprint in this part of the continent (Garreaud et al. 2012). Positive values of the SAM/AAO index have been related to warm and dry conditions over SSA due to a combination of horizontal thermal advection, subsidence (downward flux and positive SLP anomalies) and more incident solar radiation (Gillett et al. 2006; Sen Gupta and England 2006). In addition, the SAM index shows a positive trend from the late 1970 s on, most evident during DJF (Thompson and Solomon 2002; Marshall 2003), which further impels a restricted analysis of this season. The stability in time of ENSO and SAM over SSA and the interaction between these two interannual modes at regional and global scales have been the subject of previous publications, although restricted to the second half of the twentieth century and particular seasons (Silvestri and Vera 2003; Silvestri and Vera 2009; Fogt et al. 2011). Therefore, it is promising to explore the possible impact of both modes in SSA during austral summer in a long-term context.

The third motivation for this study are remote mechanisms related to the climate of eastern SSA. Teleconnections identified as Rossby waves propagating eastward over the South Pacific towards SA have raised much attention, and have been documented in connection with various phenomena occurring at different timescales and seasons. Berbery and Nogués-Paegle (1993) analysed the intraseasonal interaction mechanics between tropical heating and circulation in the $\mathrm{SH}$ for summer and winter during 1980-1987 and found the strongest relationships, including the excitation of Rossby waves, in summer. Mo and Paegle (2001) found that tropical convection, dominated by the Madden-Julian Oscillation (MJO), modulates the intraseasonal Pacific-South American modes 1 and 2 (PSA1 and PSA2) for both summer and winter during 1949-2000, in both the interannual and intraseasonal bands. These modes are connected to rainfall anomalies over northeastern Brazil, the South Atlantic Convergence Zone (SACZ), and the subtropical plains. Díaz and Aceituno (2003) 
investigated large-scale circulation anomalies linked to submonthly convective cloudiness over Uruguay during austral spring and summer between 1979 and 1993 and found a wavelike quasi-barotropic structure showing alternating centres of negative and positive geopotential height and temperature anomalies in the southern portion of the continent and farther upstream in the southern Pacific. Berman et al. (2012) found a connection during austral summer between the SESA-SACZ dipole and precipitation variability over the southernmost part of SSA during 1979-2009 through a pattern which they associated with PSA2. Focusing on temperature modulation, analysing data from the period 1979-2003, Cerne and Vera (2011) showed that the circulation anomaly which leads to heat waves over subtropical SA in the intraseasonal timescale, in association with an active SACZ, is embedded in a large-scale Rossby wave train that is linked to convection anomalies over the equatorial western and central Pacific Ocean. Nevertheless, no analysis of long-term records has been conducted in eastern SSA in order to explore to what extent teleconnection patterns similar to PSA are related to the summer-to-summer local SAT variability, which is our concrete question.

In short, since to the authors' knowledge no long instrumental records have been used for these purposes, the research in this paper focuses on the main interdecadal and interannual summertime SAT variability patterns over SSA during the twentieth century, the impacts of large-scale climate modes, and an associated teleconnection. The paper is organised as follows: Sect. 2 describes the datasets and methodology used to calculate summertime SAT indices for SSA at interannual and interdecadal timescales. The characteristics of these modes are described in Sect. 3, where we investigate interdecadal regime changes, compare our results with the PDO and Interdecadal Pacific Oscillation (IPO, Power et al. 1999), and include a brief discussion on the temporal stability of the incidence of ENSO and SAM over SSA in the interannual band. Section 4 presents local and remote relationships of the interannual SAT index with other climatic variables; in particular, a teleconnection between Oceania and SSA is described. Finally, Sect. 5 presents complementary discussions and summarizes our findings and the main conclusions.

\section{Data and methodology}

Instrumental SAT and sea level pressure (SLP) records were accessed from the global historical climatology network version 2 (GHCN; Table 1) (Peterson and Vose 1997). We also use precipitation observations from the Australian Bureau of Meteorology (Table 2) and SLP data from the New Zealand National Climate Database
(Table 3). In addition, SAT and precipitation gridded datasets were obtained from the University of Delaware (UDel, version 2.01, 1901-2008) (Legates and Willmott 1990a, b) and sea surface temperature (SST) data from ERSSTv3 (Smith and Reynolds 2004). We complement our research with different atmospheric variables from reanalysis products: ECMWF-ERA40 (1958-2002) (Uppala et al. 2005) and the twentieth century reanalysis version 2 (20CRv2, 1871-2008) (Compo et al. 2011), and also with following indices: Niño3.4 index, JISAO PDO index, and the Zhang DJF AAO index (Zhang et al. 2010). This reconstruction used for its calibration period (1957-1989) proxies that were well correlated with the observationbased Marshall AAO index (Marshall 2003). (See Acknowledgments section for details).

The datasets we use have been generated based on exhaustive research, which was aimed at including various observational systems covering the longest time period possible. For that, sophisticated methods have been applied. In the case of 20CRv2, many studies have demonstrated that reliable reanalysis of earlier periods can be generated using only surface observations and advanced data assimilation methods (Compo et al. 2011). Although the quality of 20CRv2 in the SH is still an open question, previous studies have positively assessed this product there. During 1958-1978, $300 \mathrm{hPa}$ geopotential height observations from radiosondes present higher correlations in the SH Extratropics with 20CRv2 than with ERA40 (Compo et al. 2011). For earlier periods, Brönnimann et al. (2011) found good agreement between this reanalysis and temperature observations on a cruise from Europe around South Africa and across the Indian Ocean to the western Pacific in 1906/1907, and close agreement between this reanalysis and geopotential height and temperature measurements from a cruise that traveled from Europe to Antarctica across the Atlantic and back in 1938/1939. Brönnimann and Compo (2012) found good correlations between historical ozone data and 20CRv2 over Australia and New Zealand in the 1930s. Zhang et al. (2012) found that 20CRv2 is the best suited reanalysis for investigating the climate variability over southern Africa, also highlighting its value to explore interannual to decadal variability. Furthermore, 20CRv2 has been used by studies focusing in the SH during the whole twentieth century (e.g. Wang and Cai 2013).

Nevertheless, note that station coverage is scarce in the SH compared to northern hemisphere standards, especially during early periods (late nineteenth and early twentieth centuries) and in the southern Pacific region. Thus, conclusions arising from these early times should be taken cautiously. However, in this study we describe results based on partially independent datasets in order to reduce the uncertainty associated to single products. Furthermore, 


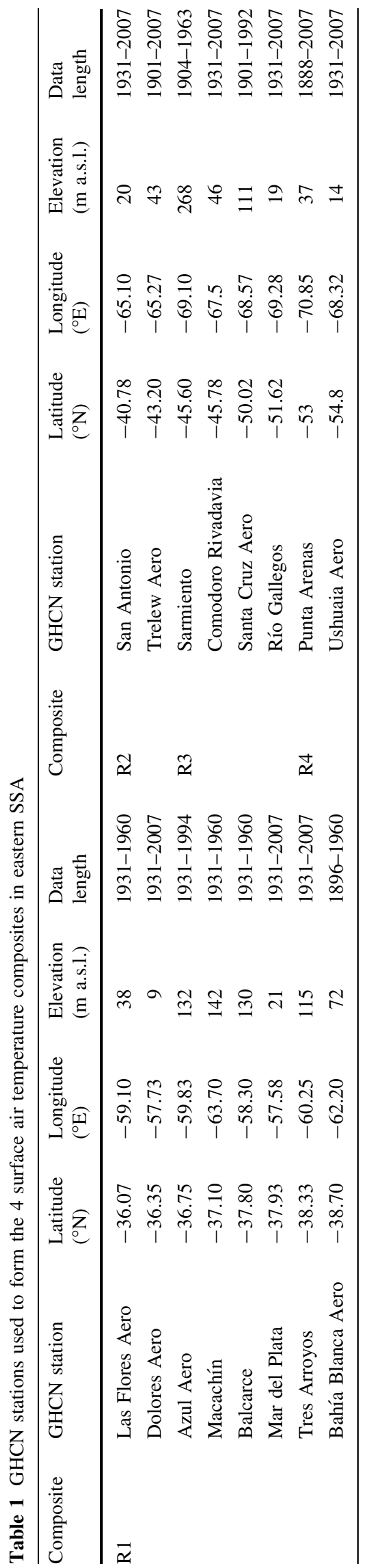

by analysing various variables at different levels, in the following we describe relationships that are consistent among them.

Our methodology consists of following steps: firstly, we formed 4 composites of austral summer (DJF) SAT time series which correspond to latitude belt averages. They group well-intercorrelated records from a total of 19 stations located next to the Atlantic coast of SSA between $36^{\circ}$ and $55^{\circ} \mathrm{S}$ [regions 1-4 (R1-R4), see Fig. 1a; Table 1]. Summer values were calculated at every station as the average value of DJF (and assigned to the corresponding JF year) from at least two values from these 3 months. Missing data for the years 1902 and 1991 from individual instrumental records were filled by means of a least-square regression on previously interpolated UDel gridded data. Individual series were normalized with respect to 1950-1979 and then averaged to form the 4 composites, covering the 1901-2007 period. Then, we substracted the long-term mean of each composite and applied a variance correction procedure (Jones et al. 1997) on the anomalies in order to reduce possible biases caused by the timevarying number of stations. We detrended the regional composites by subtracting the straight-line fit (least squares) from the data and thus removed the very low frequency variability. The resulting time series are shown in Fig. 1b. Finally, following Montecinos et al. (2003), we separated the interannual and the interdecadal variability bands by applying a 7-years running-mean twice on the detrended composite time series, which reduced the time series length to 1907-2001. Hence, we computed 4 interdecadal time series (the low-pass filtered component of the original values) and 4 interannual time series (the residuals of the detrended series minus their interdecadal components). Since in this work we deal with austral summer data (DJF), in the following the high-pass (low-pass) filtered component of the summer-to-summer time series will be denominated interannual (interdecadal) time series. We then performed a principal component analysis (PCA) on the 4 time series of each time band. The corresponding leading principal components, named $T_{-} P C{ }_{-} \_i a$ and $T \_P C 1 \_i d$, respectively, are representative of all four original regions and will be used as SAT indices of eastern SSA.

Figure 2 illustrates the application of the abovedescribed methodology on the composite of Region 3. Although its original time series (Fig. 2a) is characterised by strong year-to-year variability, its interannual component (Fig. 2b) by definition does not exhibit interdecadal fluctuations and its autocorrelation is negligible. The correlation value between this series and T_PC1_ia index (Fig. 2c) reaches $0.9^{* *}$ for 1907-2001 (statistically significant at $99 \%$; see Table 4 for all composites). 
Table 2 Stations from Australia with rainfall records used to assess the correlation with $T \_P C 1 \_i a$ and $T \_P C 1 \_i d$. The considered period results as the intersection between 1907 and 2001 (1907-1979) and the available data length for each single rainfall record

\begin{tabular}{|c|c|c|c|c|c|c|}
\hline Station name & $\begin{array}{l}\text { Latitude } \\
\left({ }^{\circ} \mathrm{N}\right)\end{array}$ & $\begin{array}{l}\text { Longitude } \\
\left({ }^{\circ} \mathrm{E}\right)\end{array}$ & $\begin{array}{l}\text { Elevation } \\
\text { (m a.s.1.) }\end{array}$ & $\begin{array}{l}\text { Data } \\
\text { length }\end{array}$ & $\begin{array}{l}\text { Interannual correlation } \\
\text { coefficient, 1907-2001 } \\
(1907-1979)\end{array}$ & $\begin{array}{l}\text { Interdecadal } \\
\text { correlation } \\
\text { coefficient, } \\
\text { 1907-2001 }\end{array}$ \\
\hline Coonabarabran P.O. & -31.28 & 149.28 & 509 & $1907-2001$ & $-0.37 * *(-0.40 * *)$ & -0.48 \\
\hline Bettowynd (Condry) & -35.70 & 149.78 & 160 & $1907-2001$ & $-0.51 * *(-0.60 * *)$ & -0.39 \\
\hline Delegate (Cometville) & -37.05 & 148.98 & 765 & $1907-2001$ & $-0.34 * *(-0.39 * *)$ & -0.48 \\
\hline Warra P.O. & -26.93 & 150.93 & 317 & $1907-1984$ & $-0.34 * *(-0.35 * *)$ & -0.41 \\
\hline Miles P.O. & -26.66 & 150.18 & 305 & $1907-2001$ & $-0.42 * *(-0.40 * *)$ & -0.48 \\
\hline Leura P.O. & -33.72 & 150.35 & 975 & 1916-1990 & $-0.43 * *(-0.45 * *)$ & -0.64 \\
\hline Cataract Dam & -34.27 & 150.80 & 340 & $1911-2001$ & $-0.49 * *\left(-0.56^{* *}\right)$ & -0.45 \\
\hline $\begin{array}{l}\text { Jervis Bay } \\
\text { (Pt Perpendicular L/H) }\end{array}$ & -35.10 & 150.80 & 085 & $1907-1998$ & $-0.32 * *(-0.42 * *)$ & -0.08 \\
\hline Moruya Head Pilot Stn & -35.92 & 150.15 & 017 & $1907-2001$ & $-0.45^{* *}\left(-0.56^{* *}\right)$ & -0.27 \\
\hline Doctors Creek & -27.20 & 151.88 & 588 & $1913-2001$ & $-0.29 * *(-0.29 * *)$ & -0.36 \\
\hline Pittsworth P.O. & -27.72 & 151.63 & 608 & $1907-2001$ & $-0.36^{* *}\left(-0.40^{* *}\right)$ & -0.05 \\
\hline Warwick (Hermitage) & -28.20 & 152.10 & 475 & 1908-1995 & $-0.38^{* *}\left(-0.38^{* *}\right)$ & -0.13 \\
\hline Warwick (Canning Downs) & -28.23 & 152.07 & 456 & $1907-2001$ & $-0.38^{* *}(-0.40 * *)$ & -0.54 \\
\hline Old Koreelah (McPherson) & -28.40 & 152.42 & 420 & 1919-2001 & $-0.43^{* *}\left(-0.45^{* *}\right)$ & -0.52 \\
\hline Port Macquaire Hill St & -31.45 & 152.92 & 007 & $1907-2001$ & $-0.34 * *(-0.38 * *)$ & -0.42 \\
\hline Lorne (Hannam Vale Rd) & -31.67 & 152.62 & 050 & $1945-2001$ & $-0.21(-0.33 *)$ & -0.60 \\
\hline
\end{tabular}

The use of one (two) asterisk(s) denotes statistical significance at $95 \%(99 \%)$ of the correlation between detrended series, considering the effective number of degrees of freedom of the data

Table 3 Stations from Australia (Darwin) and New Zealand with SLP records used to calculate the anz_index_raw (1885-2011)

\begin{tabular}{lllcl}
\hline Station name & $\begin{array}{l}\text { Latitude } \\
\left({ }^{\circ} \mathrm{N}\right)\end{array}$ & $\begin{array}{l}\text { Longitude } \\
\left({ }^{\circ} \mathrm{E}\right)\end{array}$ & $\begin{array}{l}\text { Elevation } \\
(\mathrm{m} \text { a.s.1. })\end{array}$ & $\begin{array}{l}\text { Data } \\
\text { length }\end{array}$ \\
\hline $\begin{array}{l}\text { Darwin } \\
\text { Le Bons Bay }\end{array}$ & -12.40 & 130.87 & 30 & $1867-2011$ \\
$\quad$ Aws & -43.746 & 173.119 & 236 & $1984-2011$ \\
$\begin{array}{l}\text { Lincoln } \\
\text { Lyttelton }\end{array}$ & -43.648 & 172.463 & 11 & $1885-1955$ \\
$\quad-43.608$ & 172.724 & 5 & $1971-2001$ \\
$\quad \begin{array}{l}\text { Harbour } \\
\text { Christchurch }\end{array}$ & -43.531 & 172.619 & 7 & $2003-2011$ \\
$\quad$ Gardens & & & & \\
Christchurch & -43.493 & 172.537 & 37 & $1954-2011$ \\
$\quad$ Aero & & & & \\
Lake Coleridge & -43.365 & 171.529 & 364 & $1971-1991$ \\
Reefton Ews & -42.117 & 171.86 & 198 & $2007-2011$ \\
\hline
\end{tabular}

Throughout the paper, we calculate correlation fields between $T \_P C 1 \_i a\left(T \_P C 1 \_i d\right)$ and interannual (interdecadal) time series of various variables, which have also been computed by detrending their time series and applying a 7-years running mean twice to them to separate their interannual and the interdecadal variability components. In this paper, the use of one (two) asterisk(s) denotes statistical significance at $95 \%(99 \%)$ of the correlation between detrended series, considering the effective number of degrees of freedom of the data (Bretherton et al. 1999).

For the analysis of coming sections, we identify anomalously warm and cold summers, based solely on the interannual frequency range by defining a threshold of 1 standard deviation of the T_PC1_ia index (Fig. 2c). In total, this criterion results in 14 cold and 14 warm events, which roughly correspond to the 15 and $85 \%$ percentiles of our total sample of 95 years.

\section{Summertime temperature variability over SSA}

\subsection{Description of SAT indices of eastern SSA}

The leading mode of interdecadal SAT variability over SSA, named T_PC1_id (Fig. 2d, thick black curve), explains around $80 \%$ of the original variance of the 4 interdecadal composites and suggests a frequency peak at around 64 years, which, however, cannot be statistically assessed due to limited data length. We correlate $T \_P C 1 \_i d$ with the interdecadal components of UDel SAT and ERSSTv3 for 1907-2001 (Fig. 3c). Over SA, the spatial correlation pattern shows positive coefficients over the 
(a)

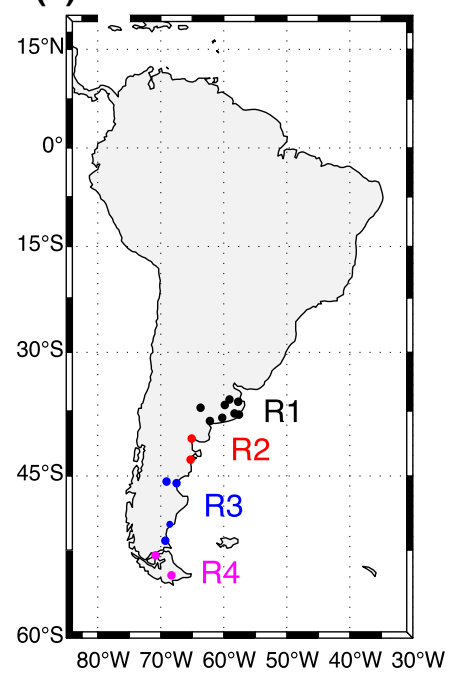

(b)

$\mathrm{R} 1$

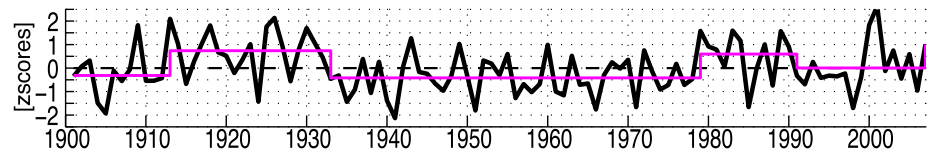

$\mathrm{R} 2$

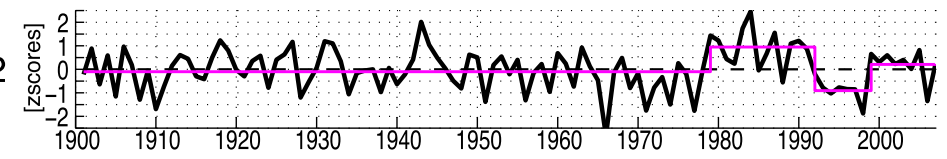

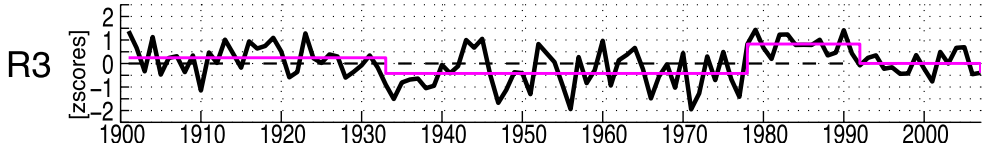

R4

Fig. 1 a Stations used to form the four meridional composites of DJF surface air temperature in eastern SSA (R1, R2, R3 and R4; see Table 1). $\mathbf{b}$ Time series of the composites, detrended and standardized

with respect to 1950-1979; magenta lines show the mean values between temperature shifts identified by the ad-hoc Rodionov test
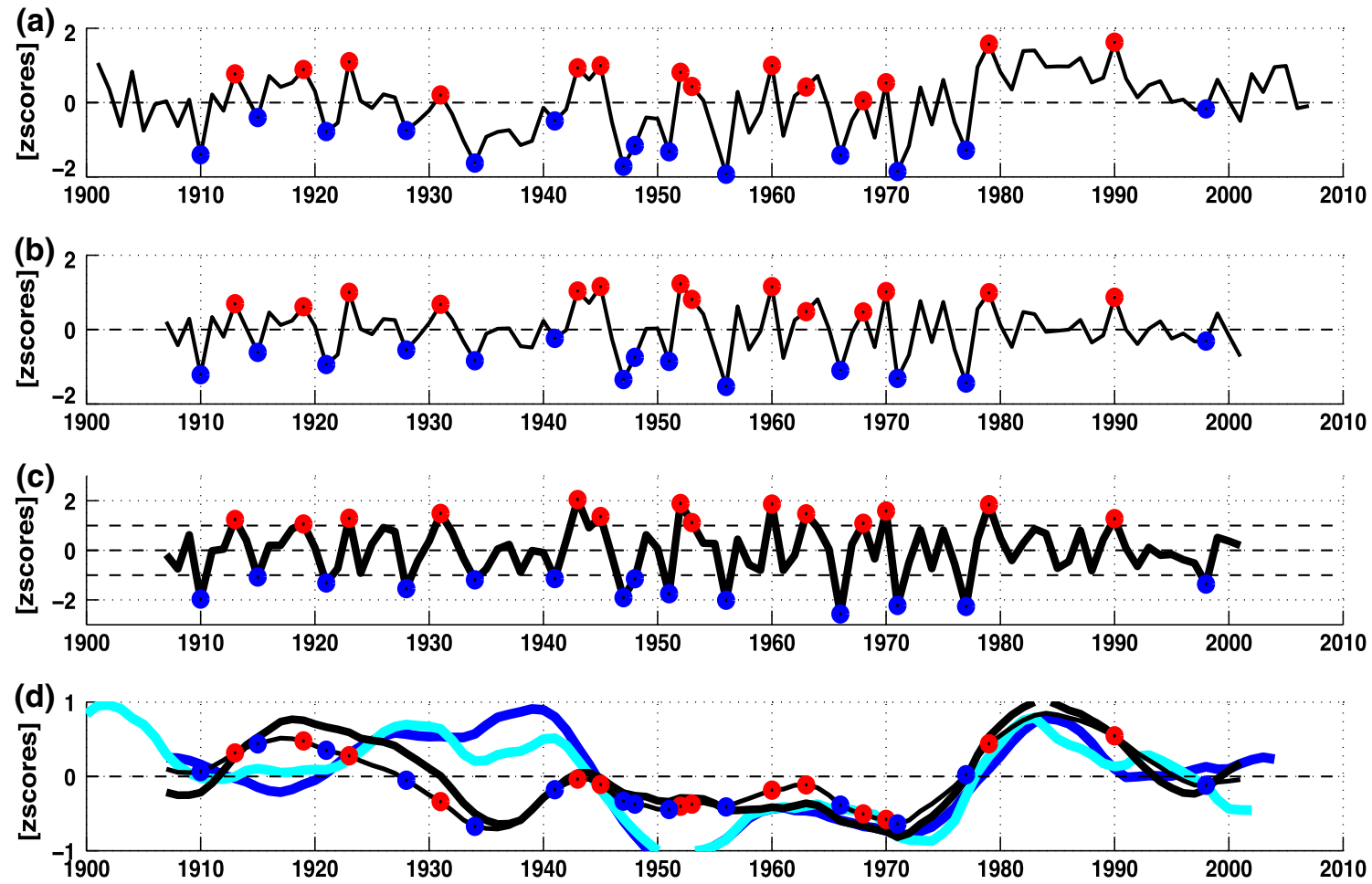

Fig. 2 a Surface air temperature time series of the composite of Region 3 (R3, see Table 1; Fig. 1), detrended and standardized with respect to 1950-1979; b residual interannual time series of Region 3, resulting from subtracting the corresponding R3 interdecadal component (d thin black curve) from the series in a); c standardized interannual $T \_P C 1 \_i a$ of SSA, and $\mathbf{d}$ standardized interdecadal
T_PC1_id (thick black curve, scaled by 0.5), interdecadal time series of Region 3 (thin black curve), and $2 \times 7$-year running mean of DJF PDO (thick blue curve) and of DJF IPO (thick cyan curve). Red (blue) markers denote years above (below) one standard deviation of $T \_P C 1 \_i a$, depicted in $\mathbf{c}$ 
Table 4 Correlation coefficients $r$ and coefficients of determination $r^{2}$ (in brackets) for the 4 composites in eastern SSA, calculated between (a) $T \_P C 1 \_i a$ and corresponding interannual indices and between (b) $T \_P C 1 \_i d$ and corresponding interdecadal indices

(a) T_PC1_ia with interannual time series

\begin{tabular}{|c|c|c|c|c|c|c|c|}
\hline & 1907-2001 & 1907-1979 & 1980-2001 & & 1907-2001 & 1907-1979 & 1980-2001 \\
\hline R1 & $0.69 * *(0.48)$ & $0.72 * *(0.52)$ & $0.73 * *(0.54)$ & R1 & $0.85(0.72)$ & $0.80 * *(0.64)$ & $0.75 * *(0.56)$ \\
\hline $\mathrm{R} 2$ & $0.84 * *(0.71)$ & $0.86^{* *}(0.74)$ & $0.85 * *(0.73)$ & $\mathrm{R} 2$ & $0.84(0.71)$ & $0.68 * *(0.46)$ & $0.99 * *(0.98)$ \\
\hline R3 & $0.90 * *(0.81)$ & $0.92 * *(0.85)$ & $0.62 * *(0.39)$ & R3 & $0.94(0.88)$ & $0.85 * *(0.72)$ & $0.86^{* *}(0.74)$ \\
\hline R4 & $0.59 * *(0.35)$ & $0.71 * *(0.50)$ & $-0.30(0.09)$ & R4 & $0.95(0.90)$ & $0.95 * *(0.90)$ & $0.84 * *(0.71)$ \\
\hline
\end{tabular}

First, second and third columns correspond to (1) 1907-2001, (2) 1907-1979 and (3) 1980-2001, respectively. The use of one (two) asterisk(s) denotes statistical significance at $95 \%(99 \%)$ of the correlation between detrended series, considering the effective number of degrees of freedom of the data

southernmost part of the continent and negatively correlated values over the Gran Chaco region, eastern Brazil and the northernmost part of SA. A hemispheric-like dipole pattern is suggested in the SST correlation field, due to the prevailing positively (negatively) correlated regions in the southern (northern) hemisphere. This meridionally asymmetric pattern shows particularly prominent positive correlation coefficients over the eastern tropical Pacific and the South Pacific, around $45^{\circ} \mathrm{S} ; 150^{\circ} \mathrm{W}$. Although the time series of $T$ PC1_id resembles the DJF PDO and IPO indices from 1960 on (both showing the 1970s phase change), this is not the case during the first half of the twentieth century (Fig. 2d). The amount of interdecadal SAT variance over SSA explained by $T_{-} P C 1 \_i d$, as measured by the coefficient of determination $\left(r^{2}\right)$, exhibits a positive North-South gradient during the period 1907-2001 (Table 4). However, while during 1907-1979 the lowest $r^{2}$ coefficient is found for R2, the opposite happens during 1980-2001. This result possibly reveals the impact of the late-1970s climate shift.

At interannual level, $T_{-} P C 1 \_i a$ explains $\sim 60 \%$ of the total variance of the 4 interannual composites and exhibits a main significant spectral peak at $\sim 3.4$ years. As shown by Fig. 3a, the correlation pattern of this index with the interannual component of the UDel SAT data exhibits a broader area of positive coefficients in SSA in comparison with the interdecadal spatial pattern of Fig. 3c. The positively correlated region corresponds roughly to the southern half of the continent, including both sides of the Andes. A dipole-like anomaly is observed between this region and eastern Brazil, a region with negative correlation coefficients. This SAT structure seems to correspond to the easternmost part of a large-scale pattern of alternating negative and positive SST anomalies extending over the South Pacific.

During 1907-2001, $T \_P C 1 \_i a$ reaches high correlation values especially with $\mathrm{R} 2$ and $\mathrm{R} 3$. This index represents 71 and $81 \%$ of the original interannual variance of these composites, respectively, whereas lower coefficients are found for R1 (48\%) and R4 (35\%). We notice that this result is similar during 1907-1979, but changes afterwards. During 1980-2001, while this index mostly reflects the interannual variability of the northern part of eastern SSA (R1: $54 \%$ and R2: $73 \%$ ), it becomes less representative for R3 (39\%) and is even anticorrelated with R4 $(r=$ $\left.-0.30 ; r^{2}=9 \%\right)$. Therefore, as for the interdecadal variability, we notice a regime difference around late-1970s. Agosta and Compagnucci (2008), describing circulation changes over SSA after the 1976/1977 summer, found an expansion of the subtropical South Atlantic anticyclone over SA and lower midlatitude cyclone activity. Jacques (2009) identified the establishment of an anticyclonic anomaly over the southern tip of SA and showed a southward shift of the westerlies during DJF after the 1970s climate shift, which resulted in weakened (enhanced) cold zonal advection over SSA between $40^{\circ}$ and $45^{\circ} \mathrm{S}$ (around $\left.53^{\circ} \mathrm{S}\right)$. The R4 composite is located where enhanced cool advection is found after late 1970s for DJF. There, temperature is anticorrelated with low-level zonal wind during this season (Garreaud et al. 2012). Hence, R4 is consequently strongly affected by the position and intensity of the westerlies. These atmospheric circulation changes seem to be at least partly responsible for the decoupling observed between R4 and the rest of the composites after late 1970s.

In order to get a deeper understanding of the spatial modes related to $T \_P C 1 \_i a$ and $T \_P C 1 \_i d$, we also perform a PCA analysis on all interannual and interdecadal UDel DJF SAT time series from SA, previously weighted by the cosine of their latitude. By doing so, resulting UDel interannual and interdecadal first (second) principal components, termed PC1s (PC2s), represent a fraction of 34.6 and $33.7 \%$ (19.6 and $12.6 \%)$ of the total continental SAT variance, respectively. The correlation coefficients between UDel interannual and interdecadal PC1s $(P C 2 s)$ and the instrumental $T \_P C 1 \_i a$ and $T \_P C 1 \_i d$ indices reach $0.62 * *$ and 0.22 (0.57** and -0.95) for the 1907-2001 period, respectively. At both timescales, the spatial correlation patterns of UDel $P C 2 s$ with UDel SAT data over SA (not shown) greatly 

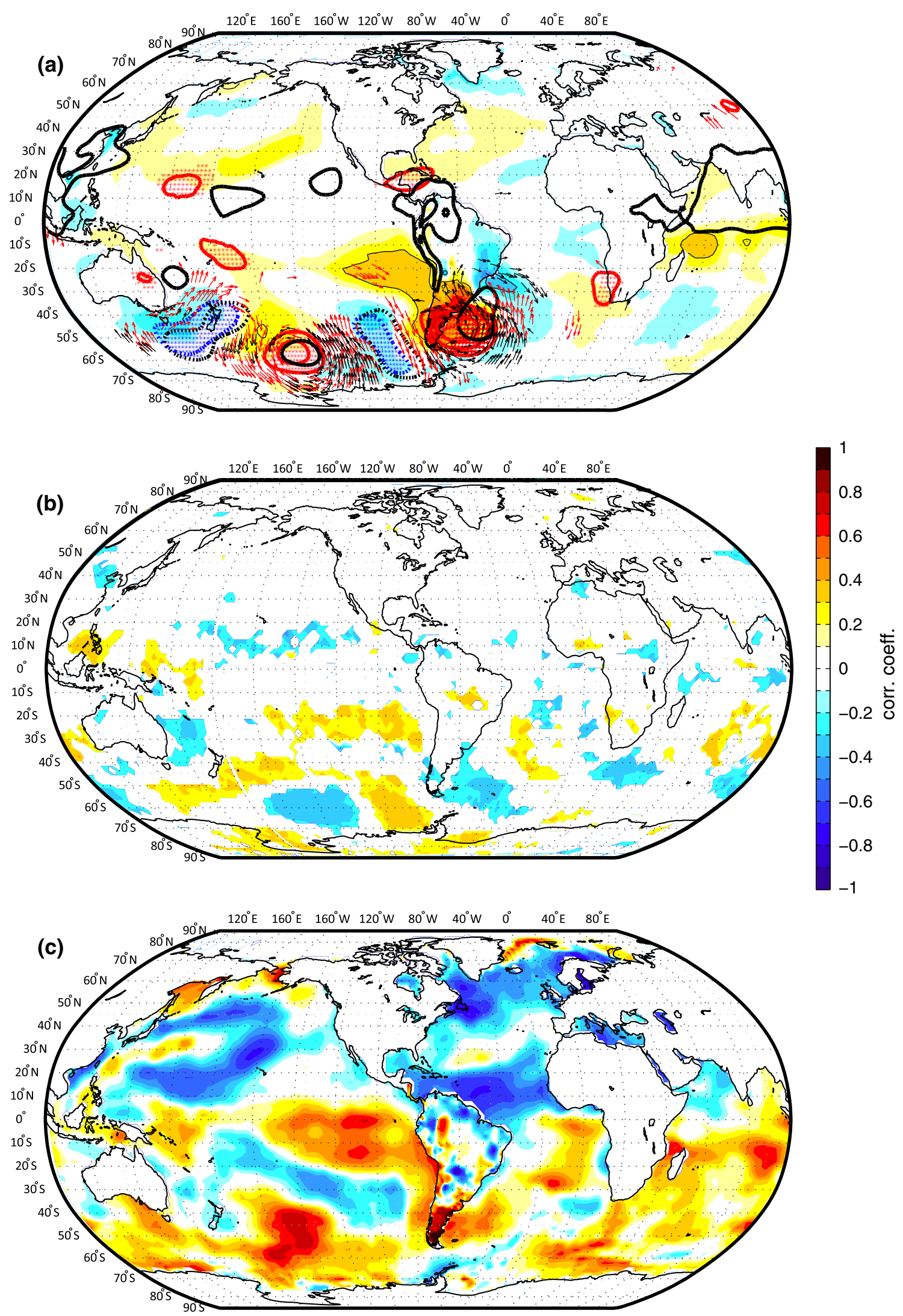
4Fig. 3 a Correlation fields of $T \_P C 1 \_i a$ with various interannual variables for the period 1907-2001. For surface air temperature over SA and SST, warm/cold colours denote positive/negative values every 0.1 (see color scale), black contours denote absolute values $>0.3$. Continuous red/dashed blue (continuous black/dashed black) contours correspond to positive/negative anomalies of geopotential height at $500 \mathrm{hPa}, \mathrm{Z} 500$ (SLP). For these two variables, contours are drawn every 0.1 for absolute values $>0.3$; zero contour omitted. Wind vectors at 850 and $200 \mathrm{hPa}$ (red and black, respectively) are drawn at gridpoints showing a correlation coefficient $>0.3$ for either their zonal or meridional components. In this case, statistical significance at $99 \%$ is reached at $\sim 0.26$ for all variables [considering autocorrelation, following Bretherton et al. (1999)]. Areas of statistically significant Z500 anomalies at $99 \%$ (1907-2000) were also assessed following the random-phase method of Ebisuzaki (1997) and are denoted by asterisks. b Correlation fields of $T_{-} P C 1 \_i a$ with the interannual relative cyclone frequency $(\mathrm{RCF}$, with respect to 1872-2008). RCF values are only shown where correlation coefficients are significant at $99 \%$ in at least $75 \%$ of the $5620 \mathrm{CRv} 2$ ensemble members. c Correlation fields of $T \_P C 1 \_i d$ with interdecadal surface air temperature and SST. Due to the strong autocorrelation of the time series, no statistical significance is reached at $99 \%$. The color scale applies to all three plots

resemble those obtained from instrumental PCls. Specifically, while UDel interannual $P C 1$ mainly represents the SAT variability over central and northeastern Argentina and Uruguay, UDel interannual $P C 2$ exhibits its highest scores over the southern tip of the continent, south of $40^{\circ} \mathrm{S}$, at both sides of the Andes. Hence, T_PC1_ia combines and synthesizes the modes of variability of these two regions. These findings confirm that SSA, which extends from the subtropics into the extratropics, exhibits in fact leading patterns of DJF SAT variability within the continent.

\subsection{On the stability of the correlations} between interannual SAT, Niño3.4 and SAM/AAO

Although the impact of ENSO in SSA is subtle, as indicated by previous studies (Aceituno 1988; Garreaud et al. 2009), we advert that the correlation coefficient between DJF Niño3.4 and T_PCl_ia shows changes in time, in particular before and after the 1970s climate shift, reaching $r=0.10$ during 1907-1979 and $r=-0.23$ during 1980-2001. The 11-years running correlation values between these indices show significant decadal fluctuations at $90 \%$ after the method proposed by Gershunov et al. (2001) (Fig. 4a). Positively correlated periods in the 1930s, 1950s, 1970s and 1980s are separated by anticorrelated periods in the 1940s, 1960s and 1990s. Hence, we conclude that there is no stable relationship between El Niño (EN) or La Niña (LN) events and SAT anomalies over SSA.

During 1907-2001, the correlation coefficient between the Zhang DJF AAO index and T_PCI_ia shows modest but significant coefficients $\left(\mathrm{r}=0.24^{* *}\right)$. However, when splitting this period, we find that the correlation values vary in time from $r=0.29 * *$ in $1907-1979$ to $r=0.09$ in
1980-2001. Hence, this suggests that the SAM-related variability is not modulating SAT in this region during 1980-2001. Furthermore, 11-years running correlation coefficients between these indices, although mostly positive during the twentieth century (Fig. $4 \mathrm{~b}$ ), show a weak decadal fluctuation, with the highest positive coefficients reached in the 1930s and 1940s $\left(r=0.59^{* *}\right.$ for 1931-1950). Interestingly, relatively high running correlation values between $T_{-} P C 1 \_i a$ and SAM are found for the anticorrelated periods calculated between $T \_P C 1 \_i a$ and the DJF Niño3.4 index, namely early 1940s and 1960s. A possible explanation of the impact of these particular periods on the link between Oceania and SA is proposed in Sects. 4.4 and 5.

\subsection{A shifty climate over SSA during the twentieth century?}

The shift observed in late 1970s in the 4 SAT composites of Fig. 1b marks the beginning of a new temperature regime. To objectively identify other possible abrupt changes in these time series, we apply an ad-hoc sequential Student's $t$ test (Rodionov 2005), considering a regime persistence of at least 10 years and a significance level of $90 \%$ (parameter values of $L=10, p=0.1$ and $h=1$, as specified therein). Besides the temperature shift in the late 1970s detected in all composites (Fig. 1b; R1: 1979, R2: 1979, R3: 1978 and R4: 1978), we identify a preceding warm-to-cold transition in all but one of them (R1: 1933, R3: 1933 and R4: 1932). Therefore, a warm-to-cold interdecadal transition took place in SSA around the beginning of the 1930s and not simultaneously with the positive-to-negative phase change of the PDO/IPO in the late 1940s (Fig. 2d). We also identify a more recent warmto-cold transition in the early 1990s in three of the composites (R1: 1991, R2: 1992, R3: 1992). Thus, we can describe the interdecadal summertime temperature variability of SSA during the twentieth century, beyond the temperature trend, as consisting of regimes separated by more or less sharp transitions, which are roughly depicted by $T \_P C 1 \_i d$. The magnitude of the late-1970s transition is, however, the greatest of the century, and its abrupt nature is clearly observed.

\section{Processes associated with interannual cold and warm summer anomalies}

4.1 Relationships of the interannual SAT index with other variables over SSA

To further explore the physical implications of the $T \_P C 1 \_i a$ signal, we correlate this index with 57 GHCN 


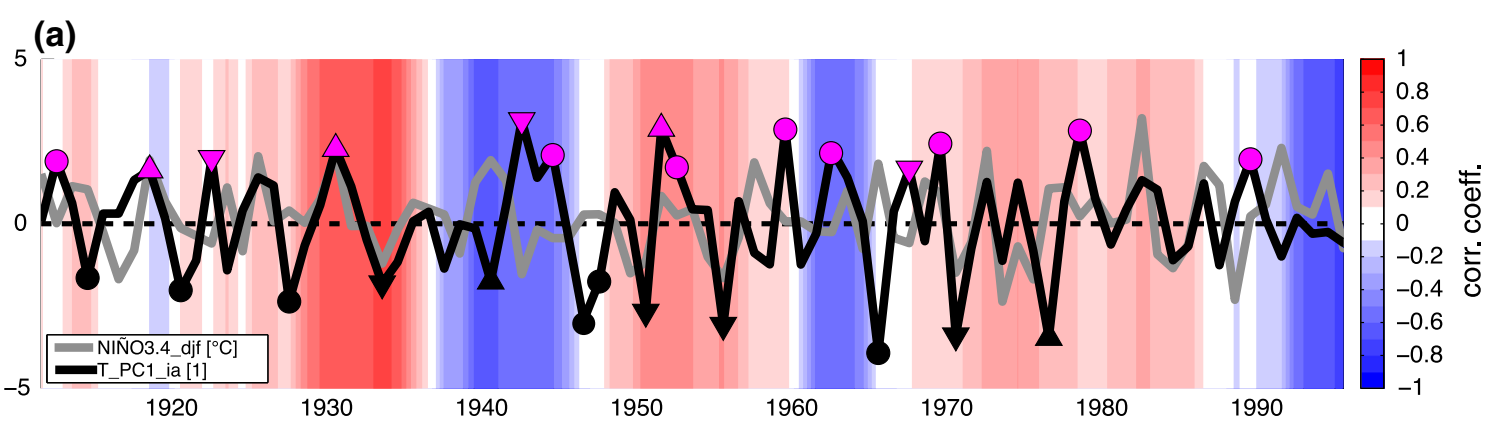

(b)

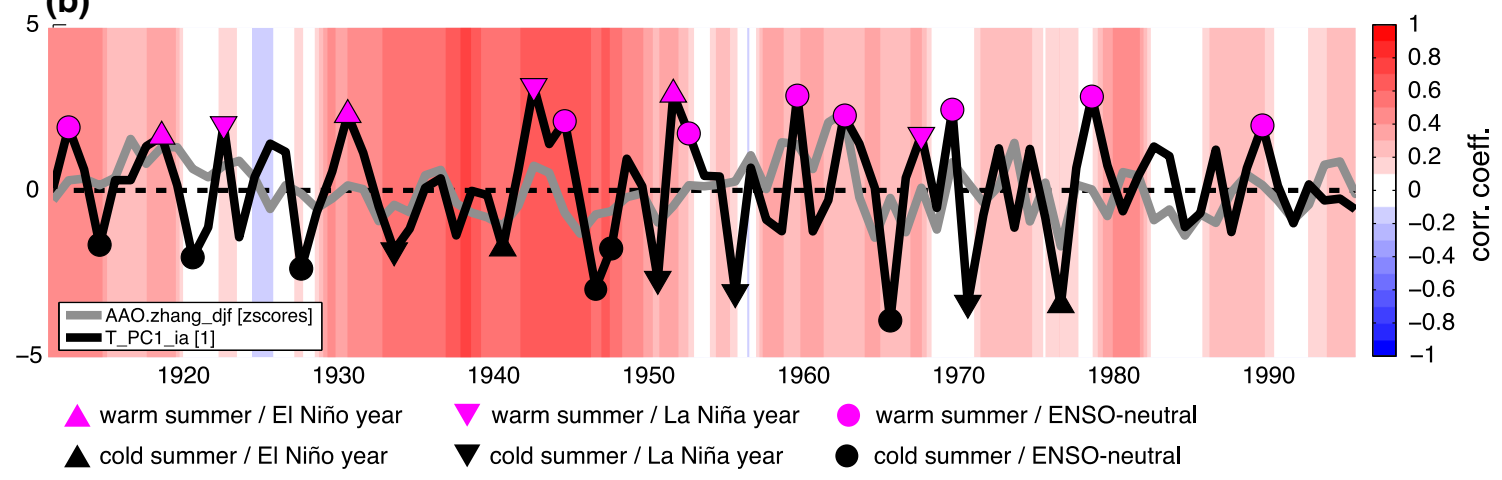

Fig. 4 Time series of T_PC1_ia (black) and a DJF Niño3.4 index (grey) and b DJF Zhang AAO index (grey). Background colors indicate the 11 -years running correlation between corresponding series, centered in the 5 th year

summer-to-summer non-filtered SLP records over the continent (Fig. 5a). Significant positive correlation coefficients are found in SSA to the East of the Andes, especially to the south of $20^{\circ} \mathrm{S}$. This result shows that warm (cold) summers in eastern SSA are linked to positive (negative) seasonal SLP anomalies there. Moreover, significant positive SLP anomalies are also found beyond that area, around $15^{\circ} \mathrm{S}$, between $50^{\circ} \mathrm{W}$ and $70^{\circ} \mathrm{W}$.

Furthermore, we also analyse the correlation field between $T \_P C 1 \_i a$ and summer-to-summer interannual DJF precipitation from gridded UDel data (Fig. 5b). The most salient features are the anticorrelated regions of southeastern SA (SESA, covering the La Plata Basin) and Patagonia. Nevertheless, also positive but weaker correlation values are found over the SACZ and central-western Argentina (CWA). Such a DJF dipole-like rainfall variability pattern between central-eastern SA and SESA was described for the intraseasonal scale by Liebmann et al. (2004) and is linked to the weakening (strengthening) of the South American low-level jet (LLJ) near $20^{\circ} \mathrm{S}$, which leads to decreased (increased) precipitation over SESA and to the contrary over SACZ. It corresponds to the South American monsoon (Liebmann and Mechoso 2011), which is the leading mode of summer precipitation over the continent, not strongly connected with ENSO (Grimm and Zilli 2009).

SESA is well known as the depository of moist and warm air from the Atlantic Ocean and the Amazon Basin, partly advected by the LLJ. This intraseasonal phenomenon, which peaks in summer, originates in the tropical Easterlies from the Atlantic Ocean that are deflected southward by the Andes. Since the highest anticorrelation values of precipitation with $T_{-} P C 1_{-} i a$ are found there, we calculate a SESA precipitation index, named sesa_P_PC1_ia, by taking the standardized PC1 of all gridpoints that show a negative correlation value of -0.4 or stronger for the period 1907-2001 there (these gridpoints are denoted by black dots in Fig. 5b; a very similar index is obtained if those time series are averaged together). By definition, the correlation value between this index and T_PC1_ia reaches a high coefficient: $-0.57 * *$ for 1907-2001. However, for the period 1907-1979 (after the 1970 s climate shift), the corresponding coefficient is $-0.66^{* *}$. This result shows the robust physical coherence of the T_PC1_ia signal in the precipitation field, highlights the imprint of higher frequency phenomena in the interannual timescale, and suggests a regime change since late1970s.

\subsection{Global correlation fields associated with the interannual SAT index}

We analyse now the global correlation fields between the interannual $T_{-} P C 1$ ia signal and SLP, geopotential height at $500 \mathrm{hPa}$ and wind fields $(u$ and $v$ ) at $850 \mathrm{hPa}$ and $200 \mathrm{hPa}$ from 20CRv2 for the 1907-2001 period, depicted in Fig. 3a. The correlation fields shown in this figure 
(a)

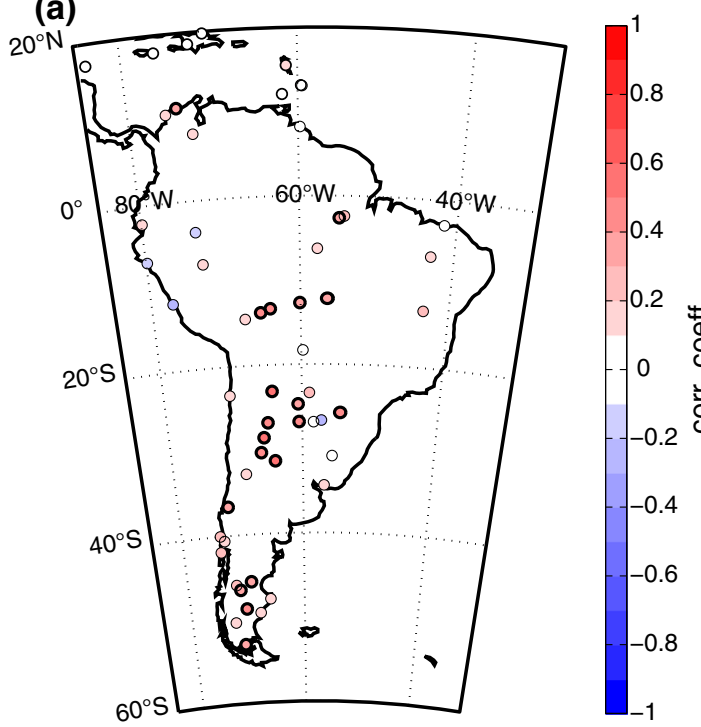

(b)

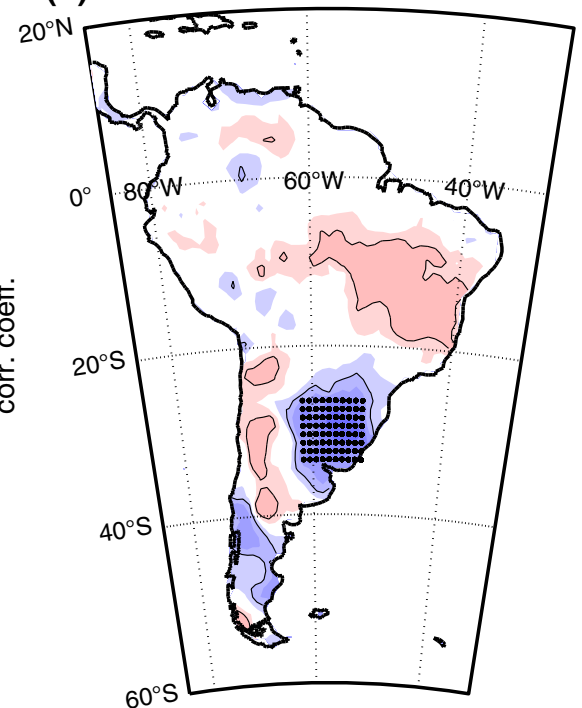

Fig. 5 a Correlation values between $T_{-} P C 1 \_i a$ and non-filtered GHCN SLP records (see color scale); statistically significant coefficients $(95 \%)$ are denoted by thick marker edges. b Correlation field of $T \_P C 1 \_i a$ with interannual UDel precipitation (see color

resemble those obtained for the shorter period 1950-1979 (not shown), which adds confidence to our results. The most striking feature we observe is a wave train pattern of barotropic structure that extends from Australia to SA along the South Pacific. To the East of the Andes Cordillera, it shows a baroclinic structure. Thus, SAT anomalies over SSA associated with $T_{-} P C 1 \_i a$ are linked to the alternation of large-scale circulation action centres. In particular, warm (cold) summers over SSA correspond to positive (negative) geopotential height and SLP anomalies, with mean positions over eastern Australia $\left(24^{\circ} \mathrm{S} ; 144^{\circ} \mathrm{E}\right)$, to the north of the Ross Sea $\left(56^{\circ} \mathrm{S} ; 152^{\circ} \mathrm{W}\right)$, and to the east of SSA $\left(46^{\circ} \mathrm{S} ; 58^{\circ} \mathrm{W}\right)$, and negative (positive) anomalies to the west of New Zealand $\left(42^{\circ} \mathrm{S} ; 172^{\circ} \mathrm{E}\right)$ and over the South Pacific, west of SSA $\left(46^{\circ} \mathrm{S} ; 106^{\circ} \mathrm{W}\right)$. Indeed, SAT and SST departures throughout this wave-train structure reveal the temperature advected by these circulation anomalies. The statistical significance of the spatial correlation patterns of $T \_P C 1 \_i a$ was assessed at $99 \%$ taking into account the serial correlation of the time series (Bretherton et al. 1999). In addition, for geopotential height at $500 \mathrm{hPa}$ during 1907-2000, we also applied the random-phase method proposed by Ebisuzaki (1997) and determined a statistically significant relationship at $99 \%$ between $T_{-} P C 1 \_i a$ and the centres of action of the wave train pattern.

We compare these results with those obtained from ERA40 for SLP and geopotential height at $500 \mathrm{hPa}$. For that, we split the 20CRv2 fields into two periods, 1907-1963 and 1964-1996. Robust signals are found in 20CRv2 for both epochs and also in ERA40 during the scale); zero contour omitted. Black contours denote absolute values $>0.2$, statistically significant at $95 \%$. Selected gridpoints in SESA are depicted by black dots; their leading principal component defines the interannual sesa_P_PC1_ia index

overlapping second period, for which both datasets qualitatively agree (not shown). Although both datasets are still comparable when choosing a shorter second period (1970-1996), the imprint of the positive trends of SAM and PDO trends is stronger in this case and tends to weaken the wave train pattern in SLP and geopotential height at $500 \mathrm{hPa}$.

Furthermore, we also identify the wave train pattern in the correlation field between $T_{-} P C I_{-} i a$ and the relative cyclone frequency (RCF), a dataset calculated with respect to the period 1872-2008 (Fig. 3b), which was generated using a cyclone identification algorithm on the 6-hourly SLP fields of the 56 members of the 20CRv2 ensemble (Welker and Martius 2012). In this case, correlation coefficients are only shown where they are significant at $99 \%$ in at least $75 \%$ of the $20 \mathrm{CRv} 2$ ensemble members. The spatial correlation pattern observed between $T_{-} P C 1 \_i a$ and $\mathrm{RCF}$ is coherent with the signal observed in the $500 \mathrm{hPa}$ geopotential height field. Our interpretation is that blocking (cyclonic anomalies) induced by the presence of ridges (troughs) throughout the troposphere to the North of the Ross Sea and East of SSA (over New Zealand and west of SSA), associated with the wave train pattern, is linked to the meandering shape of the polar front and the polar upper level jet in Fig. 3a, contrasting with their more zonal climatological shape, shown for the latter e.g. by Gallego et al. (2005). The correspondence between correlation fields obtained between $T \_P C 1 \_i a$ and geopotential height at $500 \mathrm{hPa}$ and between $T \_P C 1 \_i a$ and the RCF reveals that, beyond 
the agreement between seasonal means, the synoptic activity depicted by the cyclone frequency is linked to the DJF SAT variability over eastern SSA. This aspect seems to point to persistent circulation anomalies. Although derived from the same reanalysis product, this result further emphasizes the connection between synoptic and interannual anomaly patterns.

The linear components of the spatial correlation patterns of $T \_P C 1 \_i a$ with some variables are analysed by means of the warm-minus-cold composite difference fields. For its calculation, we considered extreme events of this index, as described in Sect. 2 (depicted in Fig. 2c). In Fig. 6a, b, we can observe that the upper- and low-level wind anomalies in the SH, between Australia and SA, resemble the wave train pattern as expected from geostrophic balance. The strong upper-level easterly (negative) anomaly over SSA around $40^{\circ} \mathrm{S}$ results from the anticyclonic anomaly over the southern tip of the continent and the Southwestern Atlantic. There, it implies the southward shift of the upper-level Polar Front Jet, due to a reduced meridional gradient of geopotential heigth at that latitude and to a stronger gradient to the South (Fig. 6c). We observe an enhancement of the prevailing low-level westerlies over the Drake Passage. A positive anomaly of low-level meridional wind is observed over eastern Brazil and subtropical SA. This pattern, together with the dipole of zonal wind anomalies identified over those regions, imply an opposite wind pattern as the one related to the LLJ, which is characterised by a southward flow east of the Andes, which deflects more to the Southeast at the exit region of the jet into La Plata Basin (Marengo et al. 2004). Thus, these circulation anomalies result in a weakened LLJ. The SLP and geopotential height fields (Fig. 6c) clearly exhibit the wave train pattern over the South Pacific and also reveal the existence of a similar structure over the North Pacific, which does not appear in the correlation fields of Fig. 3a. Nevertheless, while in the Northern Hemisphere the pattern seems to be weaker over the North American continent, in the SH it develops until reaching SA. All these circulation anomalies are linked to a mean interannual difference of up to $1.5^{\circ} \mathrm{C}$ between warm and cold DJF composites over SSA and $-0.6{ }^{\circ} \mathrm{C}$ over eastern Brazil, at the location of the SACZ (Fig. 6d). This feature constitutes a characteristic meridional dipole pattern, observed also in the correlation fields of Fig. 3a and linked to the interannual rainfall variability during DJF, as already discussed.

The non-linear components of the fields (figures not shown) reveal that cold extreme events in SSA during summer are associated with stronger circulation anomalies related to the wave train pattern than their warm counterparts, and that these groups of extreme events are not exactly linearly associated to SST perturbations along the equatorial Pacific.

\subsection{The imprint of the teleconnection in Oceania}

We suggest that the circulation anomalies induced by the wave train pattern could drive the atmospheric covariability over Oceania and SSA, e.g. by modifying convection and moisture transport, and thus affecting cloudiness and precipitation. Hence, we analyse the spatial correlation pattern between $T \_P C l \_i a$ and DJF interannual precipitation over Australia from UDel. This variable exhibits a weak zonal dipole pattern, with negative (positive) coefficients over the eastern (western) region of the country (Fig. 7a). Therefore, we calculate the standardized PC1 of precipitation from the 10 most anticorrelated gridpoints of Southeastern Australia (anticorrelation higher than -0.4 , denoted by black squares in the map), which define the aus_P_PC1_ia index (Fig. 8a). So, by definition, the significant correlation value between $T_{-} P C C_{-} i a$ and $a u s_{-}$ $P \_P C 1 \_i a$ reaches $\mathrm{r}=-0.51^{* *}\left(-0.59^{* *}\right)$ for $1907-2001$ (1907-1979), supporting the existence of a teleconnection that dynamically links both signals.

The correlation fields between aus_P_PCl and various variables (Fig. 7b) exhibit indeed a similar wave train pattern as the one observed for $T_{-} P C I_{-} i a$ (Fig. 3a, note the reversed signs), showing in this case stronger (weaker) action centres over Oceania (South Pacific). A striking difference with Fig. 3a, however, resides in the ENSO (LN) signal observed in SST for this case. While it is known that ENSO variability is asymmetrically correlated with precipitation in eastern Australia (Cai et al. 2010), temperature over SSA does not show a strong relationship with ENSO (Garreaud et al. 2008), as already showed in previous sections. In order to explore the existence of the teleconnection beyond reconstructed data, we calculate the correlation coefficients between $T_{-} P C 1 \_i a$ and precipitation records from various stations located in SE Australia (Table 2). We find lower but comparable correlation values (coloured circles in Fig. 7a) as with aus_P_PC1_ia.

Furthermore, the associated atmospheric circulation variability is analysed through the anz_index_raw, defined for 1885-2011 as a linear combination of standardized SLP records from Darwin in Northern Australia and a composite of seven stations in New Zealand (Table 3). So defined, this index measures the SLP variability over one action centre of the wave-train patterns depicted in Figs. $3 \mathrm{a}$ and $7 \mathrm{~b}$. In this case, we again calculate the interdecadal and interannual components of anz_index_raw, named anz_index_id and anz_index_ia, respectively. The correlation coefficient between anz_index_ia and T_PC1_ia (Fig. 8b) reaches $\mathrm{r}=0.39^{* *}\left(0.45^{* *}\right)$ for the 1907-2001 (1907-1979) period. Moreover, the correlation coefficients between anz_index_ia and aus_P_PC1_ia (Fig. 8c) are $\mathrm{r}=-0.65^{* *}\left(-0.74^{* *}\right)$ for the 1907-2001 (1907-1979) period. This result highlights the fact that rainfall 


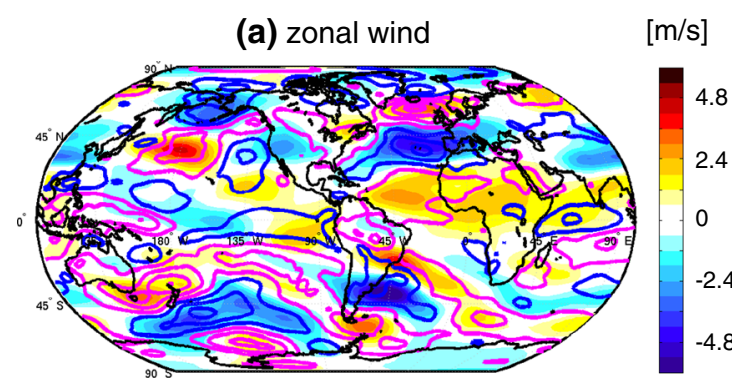

(c) SLP and gph at $500 \mathrm{hPa}$

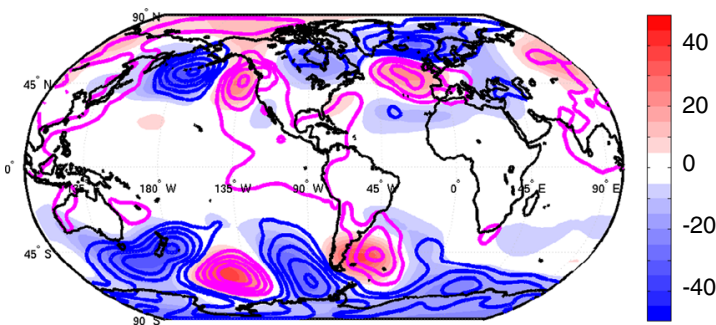

Fig. 6 Warm-minus-cold composite difference fields of interannual variables, calculated from years exceeding 1 standard deviation of the T_PC1_ia time series (Fig. 2c): a zonal wind at $200 \mathrm{hPa}$ (filled) and $850 \mathrm{hPa}$ (contours), b meridional wind at $200 \mathrm{hPa}$ (filled) and $850 \mathrm{hPa}$ (contours), c geopotential height at $500 \mathrm{hPa}$ (filled) and SLP

variability in SE Australia is partly accounted by this SLP modulation. In fact, as expected from found relationships, the two most negative years of anz_index_raw are 1887 and 1890 , when major floods were documented in eastern Australia.

\subsection{Stability of the Oceania-SSA teleconnection}

We notice that some of the $T \_P C 1 \_i a$ years agree better with aus_P_PC1_ia than others. In order to classify the extreme SAT events (as defined in Sect. 2, see Fig. 2c), a threshold of one standard deviation in the difference between the normalized series of $T_{-} P C I_{-} i a$ and $-a u s_{-}$ $P \_P C 1 \_i a$ was defined (i.e. $\mid T_{-} P C I_{-} i a+a u s_{-} P_{-}$ $P C 1 \_i a \mid \leq 1$ for well-agreeing years). Table 5 lists warm and cold summers between 1912 and 1978 after this sorting. Furthermore, neutral (n), EN, LN, and volcanic eruption (v) years were identified based on Röthlisberger (2012), who used the ENSO definition of Yeh et al. (2009) on the Met Office Hadley Centre Interpolated sea ice and SST dataset [HadISST1 (Rayner et al. 2003)] for the 1891-2006 period, and a threshold of $0.6 \mathrm{~W} / \mathrm{m}^{2}$ in the estimated solar irradiation reduction for defining $\mathrm{v}$ events, after Crowley (2000). In Fig. 9, we compare the linear component of the spatial patterns of these extreme years, calculated as the positive minus negative composite difference fields of three groups of $T \_P C 1 \_i a$ extreme years: (a) all 28 extreme years (14 positive-14 negative; similar to Fig. 6c, d; not shown), (b) 17 well-agreeing years
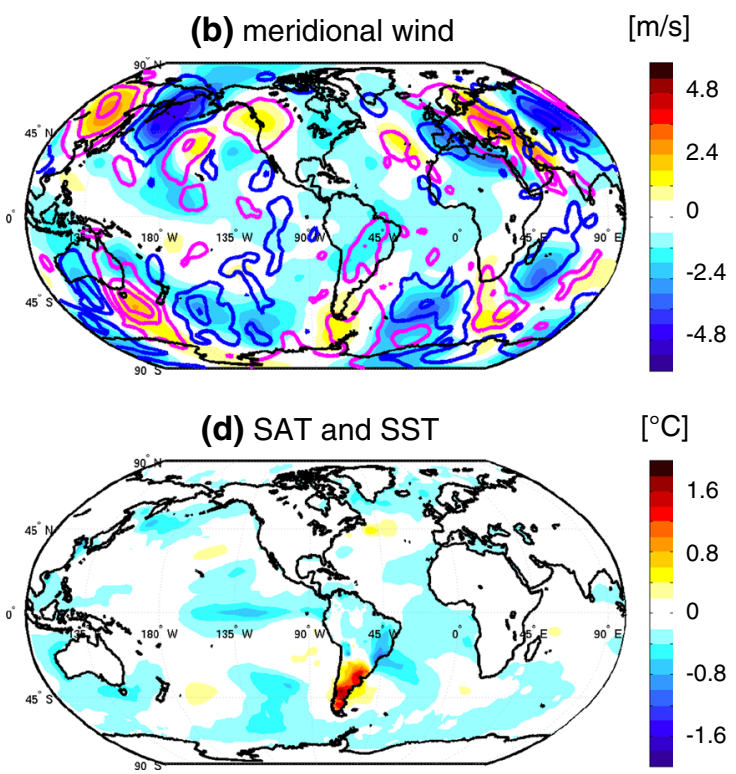

(contours), and $\mathbf{d}$ surface air temperature over SA and SST. Color scales indicate the intervals of filled contours: a, b $0.6 \mathrm{~m} / \mathrm{s}, \mathbf{c} 5 \mathrm{gpm}$, d $0.2{ }^{\circ} \mathrm{C}$. Units for not-filled contours are: a, b $0.5 \mathrm{~m} / \mathrm{s}$, c $0.5 \mathrm{hPa}$. Zero contours omitted

(9 positive-8 negative, Fig. 9a, b) and (c) 7 badlyagreeing years ( 3 positive -4 negative, Fig. 9 c, d). The badly-agreeing group clusters years which exhibit a drop in the covariability between $T_{-} P C I_{-} i a$ and $a u s_{-} P \_P C 1 \_i a$ and shows opposite SST and SAT anomalies over the tropical Pacific and SSA, respectively (Fig. 9d).

These results are summarized in an alternative manner by the 11-year running correlation values between $-a u s \_P \_P C 1 \_i a, T \_P C 1 \_i a$ and the DJF Niño3.4 index in Fig. 10 (comparable with the background of Fig. 4a). Note that during early 1940s and early 1960s the correlation coefficients between Niño3.4 and both $-a u s \_P \_P C 1 \_i a$ and $T_{-} P C 1 \_i a$ reverse sign. A similar phenomenon is observed for the 11-year running correlation coefficients between $-a u s \_P \_P C 1 \_i a$ and $T \_P C 1 \_i a$, although its decadal fluctuation just affects the amplitude and not the sign. Interestingly, these periods correspond to anomalous states of the climate system, namely after the strong and long-lasting 1940-1942 EN event (Brönnimann et al. 2004) and the major eruption of Mt. Agung in 1963, respectively. In addition, we observe in the composite of badly-agreeing years (Fig. 9c, d) a LN-like anomaly over the tropical Pacific together with a much more zonal geopotential height structure in the mid-latitudes, resembling the positive SAM phase. Furthermore, during these badly-agreeing years less dry (less wet) conditions are observed over southeast Australia, together with warm (cold) conditions over SSA. Although not evident in our results, Hendon et al. (2007) showed that during the positive SAM phase 
Fig. 7 a Correlation field of $T \_P C 1 \_i a$ with interannual UDel precipitation over Australia (see color scale). Black contours denote absolute values $>0.2$, statistically significant at $95 \%$. Black squares indicate the gridpoints used to define the aus_P_PC1_ia index (see text). Circles show the correlation coefficients for individual interannual precipitation records (see Table 2). b As Fig. 3a, but for aus_P_PC1_ia (a)
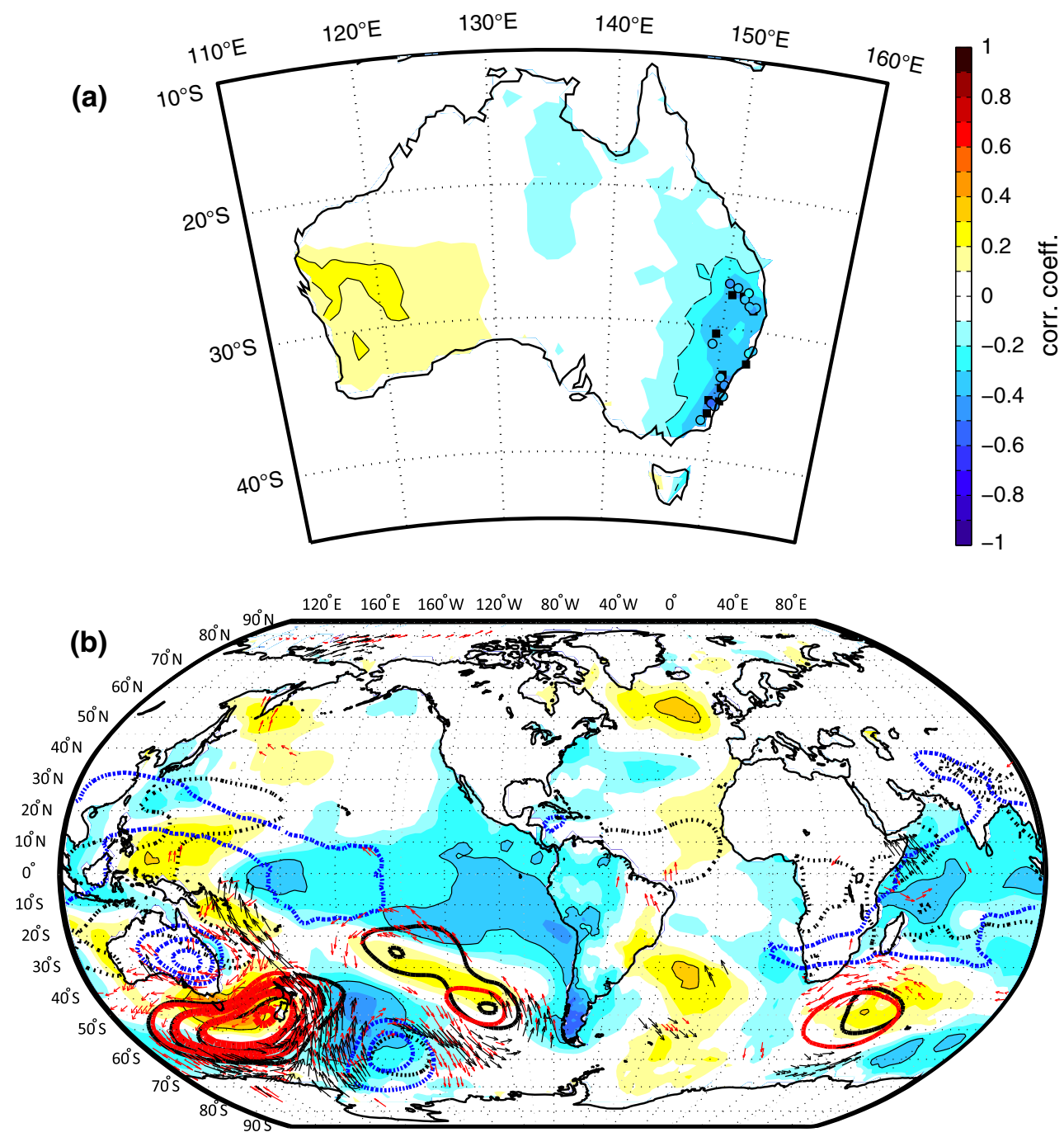

rainfall is enhanced over southeast Australia, partly due to an easterly upslope wind anomaly, which advects moisture from the Tasman Sea to the continent. Moreover, Fogt and Bromwich (2006) stated that high-latitude ENSO teleconnections amplify when the SAM index is positively correlated with the SOI during austral spring and summer, and L'Heureux and Thompson (2006) found a significant relationship between the warm phase of ENSO and the low index polarity of the SAM. Previous observations suggest a role of SST anomalies over the tropical Pacific in modulating the found teleconnection.

\section{Discussions and summary}

In this work, the summertime temperature signal of eastern SSA spanning the twentieth century (1907-2001) has been analysed. The interdecadal leading mode, named $T_{-} P C{ }_{-} \_i d$, explains $\sim 80 \%$ of the total interdecadal variance of the station-based composites and suggests its highest frequency peak at 64 years. Its spatial pattern shows positive coefficients over the southernmost part of the continent and negative values over the Gran Chaco region, eastern Brazil and the northernmost part of SA. This mode modulates embedded higher frequency variability and is correlated with the PDO and IPO indices since the 1960s (showing the late 1970s climate shift), but not in the first half of the twentieth century. This issue highlights the necessity of a proper definition of this particular variability mode. Besides the strong warming shift detected in T_PC1_id in the late 1970s, in 3 of 4 of our interdecadal temperature composites, we observe a warm-tocold shift-like transition in the early 1930s (and not in the late 1940s, as expected from a possible PDO-related or IPOrelated variability) and a more recent abrupt warm-to-cold phase change in the early 1990s. Thus, we conclude that the interdecadal SAT variability in SSA during the twentieth century consists of regimes separated by more or less sharp transitions.

The main focus of this paper, however, is the interannual summertime SAT variability over SSA. The corresponding 
Fig. 8 Normalized time series of T_PC1_ia (SSA red), $a u s \_P \_P C 1 \_i a$ (E. Australia blue), and anz_index_ia (Australia-New Zealand black). In a extreme years of $T \_P C 1 \_i a$ are indicated (see legend at the bottom). Correlation values (all statistically significant at $99 \%$ ) for 1907-2001 (1907-1979) are shown

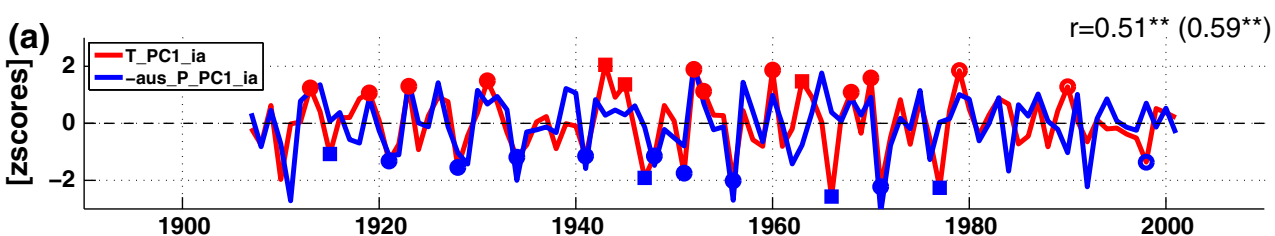

(b) $\quad r=0.39^{\star \star}\left(0.45^{\star \star}\right)$
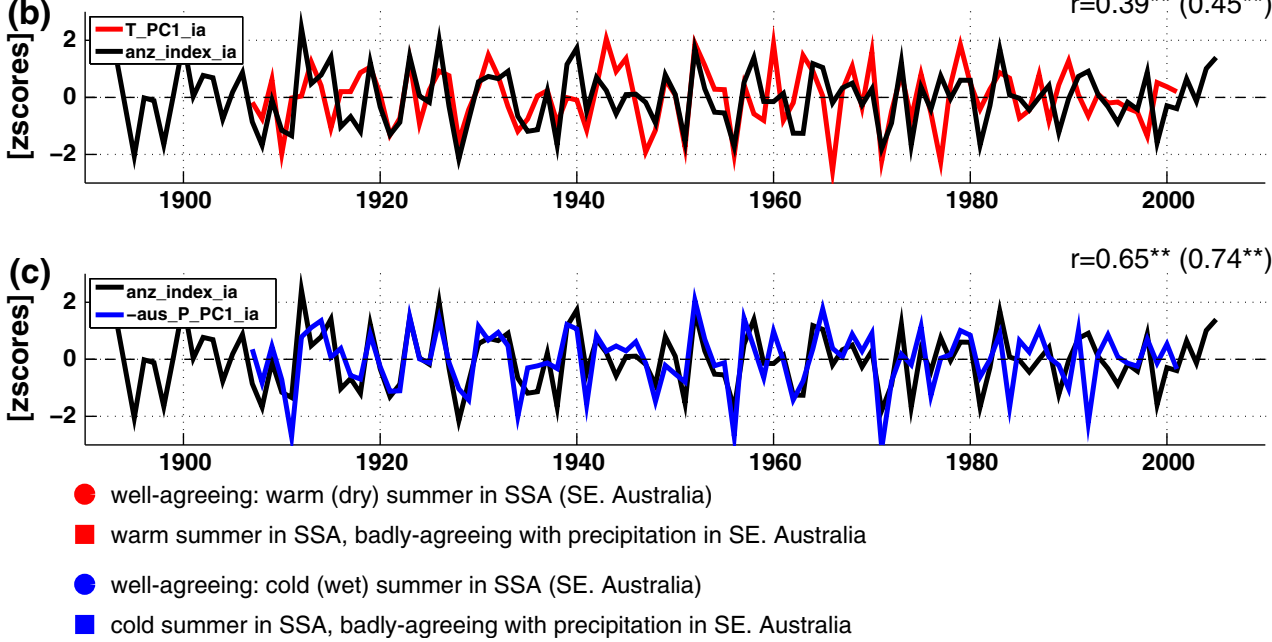

Table 5 Well- and badly-agreeing extreme summers (see text for definition)

\begin{tabular}{|c|c|c|c|c|c|c|c|}
\hline \multicolumn{4}{|c|}{ Well-agreeing extreme years } & \multicolumn{4}{|c|}{ Badly-agreeing extreme years } \\
\hline \multicolumn{2}{|c|}{ Positive difference (SD) } & \multicolumn{2}{|c|}{ Negative difference (SD) } & \multicolumn{2}{|c|}{ Positive difference (SD) } & \multicolumn{2}{|c|}{ Negative difference (SD) } \\
\hline 1913 & $0.13(\mathrm{w}, \mathrm{v})$ & 1951 & $-0.96(\mathrm{c}, \mathrm{LN}, \mathrm{SAM}-)$ & 1945 & $1.07(\mathrm{w}, \mathrm{n})$ & 1966 & $-2.95(\mathrm{c}, \mathrm{v})$ \\
\hline 1919 & $0.19(\mathrm{w}, \mathrm{EN}, \mathrm{SAM}+)$ & 1928 & $-0.51(\mathrm{c}, \mathrm{n})$ & 1943 & $1.77(\mathrm{w}, \mathrm{LN})$ & 1977 & $-2.30(\mathrm{c}, \mathrm{EN}, \mathrm{SAM}-)$ \\
\hline 1968 & $0.21(\mathrm{w}, \mathrm{LN})$ & 1921 & $-0.20(\mathrm{c}, \mathrm{n})$ & 1963 & $2.24(\mathrm{w}, \mathrm{n}, \mathrm{SAM}+)$ & 1947 & $-1.78(\mathrm{c}, \mathrm{n})$ \\
\hline 1948 & $0.33(\mathrm{c}, \mathrm{n})$ & 1923 & $-0.19(\mathrm{w}, \mathrm{LN})$ & & & 1915 & $-1.14(\mathrm{c}, \mathrm{v})$ \\
\hline 1953 & $0.42(\mathrm{w}, \mathrm{n})$ & 1952 & $-0.18(\mathrm{w}, \mathrm{EN})$ & & & & \\
\hline 1941 & $0.44(\mathrm{c}, \mathrm{EN}, \mathrm{SAM}-)$ & & & & & & \\
\hline 1970 & $0.68(\mathrm{w}, \mathrm{v}, \mathrm{SAM}+)$ & & & & & & \\
\hline 1956 & $0.68(\mathrm{c}, \mathrm{LN})$ & & & & & & \\
\hline 1934 & $0.81(\mathrm{c}, \mathrm{LN})$ & & & & & & \\
\hline 1931 & $0.81(\mathrm{w}, \mathrm{EN})$ & & & & & & \\
\hline 1960 & $0.89(\mathrm{w}, \mathrm{n}, \mathrm{SAM}+)$ & & & & & & \\
\hline 1971 & $0.90(\mathrm{c}, \mathrm{LN})$ & & & & & & \\
\hline
\end{tabular}

Only warm (w) and cold (c) events between 1912 and 1978 have been considered and then classified as neutral (n), El Niño (EN), La Niña, and volcanic eruption (v) years. Positive (negative) DJF SAM phases correspond to departures greater than $+1(-1)$ SD of the DJF Zhang AAO index (reference period: 1907-2001)

index, named T_PCl_ia, represents $\sim 60 \%$ of the interannual variance of our composites in this frequency range and exhibits its highest significant peak at $\sim 3.4$ years. Spatially, this mode represents the variability of roughly the southern half of SA and corresponds to one of the main SAT variability modes of the whole continent.

A barotropic wave train pattern, extending from Oceania along the South Pacific to SSA, is the main large-scale feature associated with $T_{-} P C C_{-} i a($ Fig. 3a). The wavetrain- like pattern we identified at $500 \mathrm{hPa}$ resembles that described by Cerne and Vera (2011) when studying the influence of intraseasonal variability in the development of heat waves over subtropical SA in summer in connection with an active SACZ, i.e. increased convection leading to more precipitation in this area. For that, these authors used SAT data from just one station located in Rosario, Argentina $\left(32^{\circ} 55^{\prime} \mathrm{S}, 60^{\circ} 47^{\prime} \mathrm{W}, 25 \mathrm{~m}\right.$ a.s.l.), and the NCEPNCAR reanalysis for the 1979-2003 period. However, we 
well-agreeing years' difference

(a) SLP and gph at $500 \mathrm{hPa}$

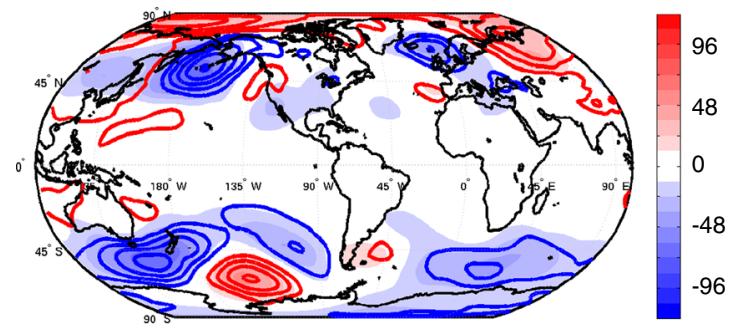

badly-agreeing years' difference

(c) SLP and gph at $500 \mathrm{hPa}$

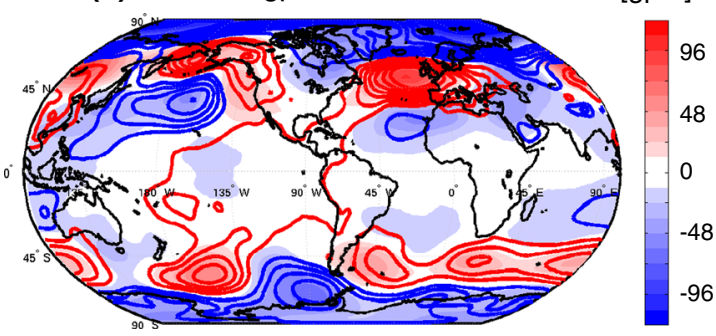

Fig. 9 Composite difference fields (positive-negative) of interannual DJF variables, considering following groups of extreme events listed in Table 5 and depicted in Fig. 8a: a, b well-agreeing years, and $\mathbf{c}$, d badly-agreeing years between $T \_P C 1 \_i a$ and $a u s \_P \_P C 1 \_i a$. (b) SAT and SST

$\left[{ }^{\circ} \mathrm{C}\right]$

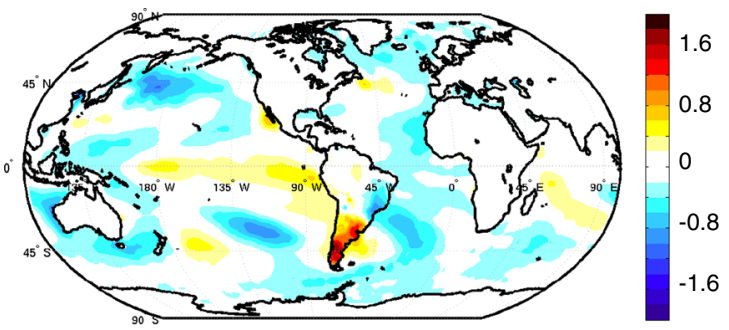

(d) SAT and SST

$\left[{ }^{\circ} \mathrm{C}\right]$

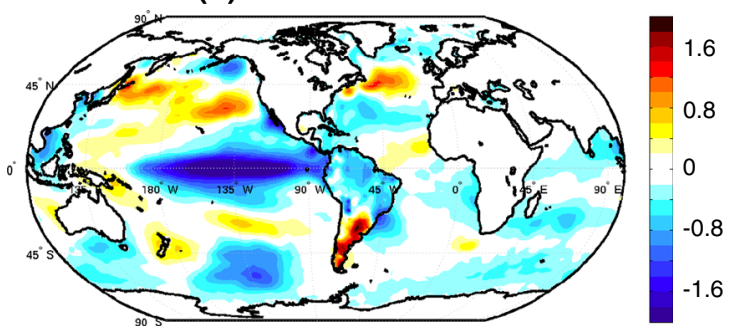

Anomaly fields correspond to: a, c geopotential height at $500 \mathrm{hPa}$ (filled contours, every $12 \mathrm{gpm}$ ) and SLP (simple contours, every $1 \mathrm{hPa}$ ); b, d SST and surface air temperature over SA (every $0.2^{\circ} \mathrm{C}$ ). Zero contours omitted
Fig. 10 Time series of 11-year running correlation coefficients (1912-1996) centered in the 5th year between DJF Niño3.4 and: a T_PC1_ia (thick solid curve) and $\mathbf{b}-a u s \_P \_P C 1 \_i a$ (dashed curve). The 11-year running correlation coefficients calculated between $T \_P C 1 \_i a$ and $-a u s \_P \_P C 1 \_i a$ are also shown (thin solid curve). Red/ blue markers denote warm/cold events listed in Table 5 (see legend at the bottom)

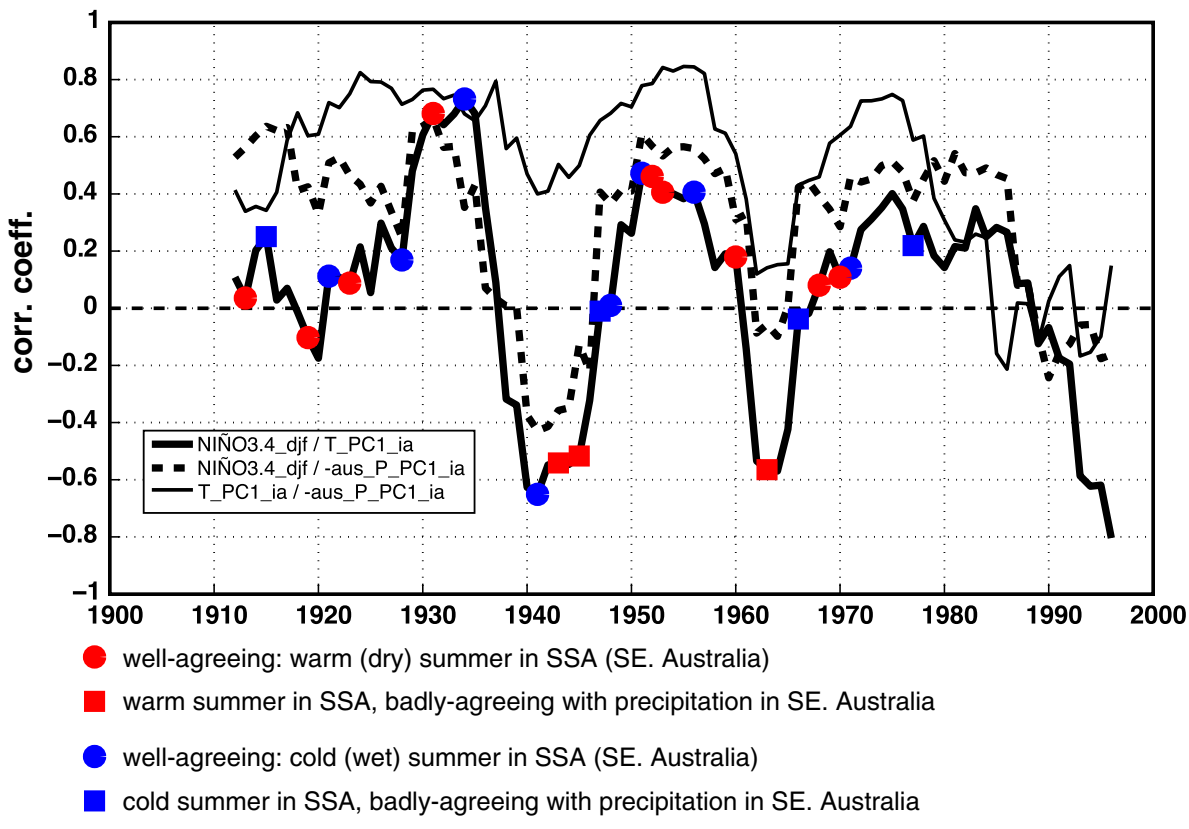

advert a different phasing of the wave-train pattern linked to $T_{-} P C 1 \_i a$; that is, the location of the action centres of the corresponding large-scale anomalies differ between that study and the results presented here. Furthermore, Díaz and Aceituno (2003), in their study about enhanced (wet) and reduced (dry) episodes of convective cloudiness over Uruguay during the period 1979-1993, showed a wavelike structure in 11-day composites of $200 \mathrm{hPa}$ geopotential height anomalies. Our results resemble their sub-monthly signal for dry conditions over Uruguay. In this way, we extend the results of previous papers into longer timescales by studying SAT variability over SSA during almost the whole twentieth century.

The climatic implications of $T_{-} P C 1 \_i a$ were also investigated through the relationships between this index and SLP and precipitation time series from SA. In 
particular, the spatial correlation pattern with rainfall reveals the dipole between SESA and the SACZ, associated with the South American monsoon (Liebmann and Mechoso 2011). Doyle and Barros (2002) showed, for January, a positive feedback between weak (intense) SACZ activity and positive (negative) SST anomalies over the western subtropical South Atlantic Ocean (WSSA: $20^{\circ}-$ $\left.30^{\circ} \mathrm{S} ; 30^{\circ}-50^{\circ} \mathrm{W}\right)$. In agreement with this, we observe in Figs. $3 \mathrm{a}$ and $5 \mathrm{~b}$, respectively, that the dry (wet) anomaly over SESA and wet (dry) anomalies over SACZ and CWA are concomitant with a cold (warm) anomaly over WSSA. We also note that such SST anomaly has at least partly an advective origin due to the anticyclonic circulation observed to its Southwest, which is indeed part of the described wave train pattern. The SACZ-SESA rainfall dipole, which modulates heavy precipitation events, has been identified also in connection with DJF sub-monthly variations of cloudiness (from 2 to 30 days) and referred to as the South American Seesaw Pattern (Nogués-Paegle and Mo 1997; Liebmann et al. 1999). Liebmann et al. (1999), showed a wave train in the $200 \mathrm{hPa}$ streamfunction over the South Pacific, starting near New Zealand towards SA. They characterised it as a zonal wavenumber- 5 pattern that occurs frequently within the austral westerlies, especially during summer (Kidson 1991), and referred to the Rossby wave guide along the South Pacific jet into the subtropics of the South Atlantic identified by Ambrizzi and Hoskins (1997) during austral summer as a preferred route of energy dispersion. Although derived from a submonthly signal associated to another variable in a different region as ours, and analysing the streamfunction at $200 \mathrm{hPa}$ instead of geopotential height at $500 \mathrm{hPa}$, the wave train pattern of Liebmann et al. (1999) is comparable to the circulation pattern associated to our results, especially when their fields are lagged by -4 to -2 days with respect to the OLR signal. However, the strongest anomalies are, as expected, located where each signal originates. This supports the conclusion that our results are linked to findings by previous studies (in particular, the SACZ-SESA dipole shown in our Fig. 5), and that our approach (SAT seasonal analysis) masks the synoptic evolution of this teleconnection. At synoptic scale, Liebmann et al. (2004) showed that the intensity of the LLJ is forced by a wave train pattern that originates at midlatitudes over the Pacific Ocean, and then deflects equatorward after crossing the Andes Cordillera. These authors proposed that the MJO could modify the planetary basic-state flow, which would lead to a preferred phasing of synoptic waves towards SA.

The correlation pattern between $T_{-} P C 1 \_i a$ and the RCF (a synoptic-to-intraseasonal phenomenon, Fig. 3b) shows that a warm (cold) anomaly over SSA is observed together with a lower (higher) frequency of cyclones over this region and the southwest Atlantic Ocean. Besides, the geopotential height and SLP correlation fields of Fig. 3a resemble features that are opposite to the pattern related to summertime incursions of cold air, which affect the whole region (Garreaud and Wallace 1998; Garreaud 2000). In particular, we observe the mid-level ridge to the east of the Andes and over the southwest Atlantic, and the positive SLP anomaly over that latter region. Thus, we clearly identify how the signals of synoptic-scale phenomena, related to both precipitation and temperature variability, propagate into longer timescales and imprint the local pattern of DJF interannual climate variability.

In this context, regional SAT implications of $T \_P C 1 \_i a$ could be associated to findings of previous studies focused on daily variability. Barrucand et al. (2008) found a 4-year signal in the occurrence of warm days and cold nights during summer for 1964-2003 and a decrease of the latter variable during 1964-1979. These results agree with the variability peak at $\sim 3.4$ years of $T_{-} P C 1 \_i a$ and with the warming observed during the 1970s in $T_{-} P C 1 \_i d$, respecitvely, but a possible connection should be explored in detail.

In a broader spatial perspective, we found a negative covariability between precipitation over eastern Australia and SAT over SSA (represented by aus_P_PC1_ia and $T \_P C 1 \_i a$, respectively). Although ENSO variability is known to impact the former, such a relationship is not evident for the latter, where the 11-years running correlation coefficients between DJF Niño3.4 and T_PC1_ia exhibit significant decadal fluctuations. Thus, disruptions of the Oceania-SSA teleconnection seem to be related to SST anomalies in the tropical Pacific. Cai et al. (2001) described the non-stationarity of the relationship between ENSO and DJF precipitation in northeastern Australia. It was found that this relationship reversed sign in periods where the detrended global mean surface temperature was rising or anomalously high, as in 1931-1945. This period partially coincides with the first reversal of the running correlation values between $T_{-} P C{ }_{1} i a$ and DJF Niño3.4 and the strengthening of the relationship between $T \_P C 1 \_i a$ and DJF SAM/AAO (Figs. 4, 10), which also occurs in the 1960s. In both periods, the low-pass-filtered SOI index shows anomalously low values [e.g. Power et al. (2006)]. Moreover, Cai et al. (2010) studied the asymmetry of the relationship between ENSO and DJF precipitation in the eastern part of Australia (Southeast Queensland, SEQ) during 1950-1979 and found that, while LN events result in increased rainfall in that region, no robust signal exists for EN events. This study states, however, that before the mid-1930s and since the 1980s, this asymmetry no longer operates. This fact has caused a dramatic local rainfall reduction since then. They associate this breakdown partly to an eastward shift of the Walker circulation (and, consequently, an increase of the amplitude of LN Modoki 
thereafter) and of the convection centre near SEQ (particularly the South Pacific Convergence Zone), which they relate to a positive phase of the IPO (PDO). In summary, the new mean position of the main convection centre over the tropical Pacific, related to the EN-like climate background after late 1970s (Mantua et al. 1997), seems to have modified the position of the action centres of the wave train pattern and its related dynamics. Hence, while after the 1970s shift this mechanism still appears to drive the interannual SAT variability over SSA, it would have stopped modulating the precipitation variability over eastern Australia, thus breaking the Oceania-SSA teleconnection documented here.

To this respect, Agosta and Compagnucci (2011) found that the precipitation variability of CWA [spanning $\left(29-36^{\circ} \mathrm{S} ; 65-70^{\circ} \mathrm{W}\right)$ in their case], positively correlated with $T \_P C 1 \_i a$ (Fig. $5 \mathrm{~b}$ ), was associated with a barotropic quasi-stationary wave emanating from the tropical Indian Ocean and the South Pacific from the beginning of the twentieth century until mid-1970s. After the 1976/77 climate shift, however, they identified the EN-like conditions over the tropical Pacific and the possibly related strengthening of the Subtropical Atlantic Anticyclone as factors modulating the CWA precipitation variability. We found that the interdecadal precipitation variability of CWA (UDel data) greatly resembles T_PC1_id (not shown), although showing an earlier manifestation of the 1970s shift, which could be related to large-scale precipitation changes documented in the Pampean plains of Central Argentina (Piovano et al. 2002) and in the South American monsoon system (Carvalho et al. 2011). These similarities reflect the broad climatic implications of the interannual and interdecadal variability modes documented in this paper.

The results presented here contribute to a better understanding of South American climate and its dynamical connections with remote regions. In comparison with previous studies, a broader spatiotemporal perspective has been introduced by using long instrumental records from this relatively poorly instrument-covered region and by means of the novel 20CRv2 reanalysis.

Acknowledgments The authors would like to thank the availability of the Niño3.4 index (http://www.cgd.ucar.edu/cas/catalog/climind/ TNI_N34/index.html\#Sec5), the PDO index (http://jisao.washington. edu/pdo/PDO.latest), the IPO index (http://www.iges.org/c20c/IPO_v2. doc), the Zhang DJF AAO index (http://adrem.org.cn/Faculty/ GongDY/docu/AAOsince1500.htm), and the Matlab code of the Rodionov's sequential $t$ test (http://www.beringclimate.noaa.gov). The SLP time series of Darwin (Australia) has been obtained from http:// www.cgd.ucar.edu/cas/catalog/climind/darwin.ascii. SLP data from New Zealand have been accessed from http://cliflo.niwa.co.nz/ and Australian precipitation data from http://www.bom.gov.au/climate/ data/. GHCN-Monthly version 2 provided by NOAA's National Climatic Data Center (http://www.ncdc.noaa.gov/ghenm/v2.php). Twentieth century reanalysis V2 data provided by the NOAA/OAR/ESRL PSD, Boulder, Colorado, USA, from their Web site (http://www.esrl. noaa.gov/psd/). ECMWF ERA-40 data used in this study have been obtained from the ECMWF Data Server (http://data-portal.ecmwf.int/). Thanks to Prof. Dr. Olivia Romppainen-Martius, Dr. Fabia Hüsler, Dr. Christoph Welker, Dr. Alexander Stickler, Dr. Renate Auchmann, Matthias Röthlisberger and Pablo Sánchez for their support during the preparation of the manuscript. This paper was greatly improved by the comments and suggestions of two anonymous reviewers. MJC acknowledges the BecasChile scholarship program (Comisión Nacional de Investigación Científica y Tecnológica de Chile, CONICYT).

\section{References}

Aceituno P (1988) On the functioning of the Southern Oscillation in the South American sector. Part I: surface Climate. Mon Weather Rev 116:505-524. doi:10.1175/1520-0493(1988) 116<0505:OTFOTS $>2.0 . \mathrm{CO} ; 2$

Agosta EA, Compagnucci RH (2008) The 1976/77 austral summer climate transition effects on the atmospheric circulation and climate in southern South America. J Clim 21:4365-4383. doi:10.1175/2008JCLI2137.1

Agosta EA, Compagnucci RH (2011) Central-west Argentina summer precipitation variability and atmospheric teleconnections. J Clim 25:1657-1677. doi:10.1175/JCLI-D-11-00206.1

Ambrizzi T, Hoskins BJ (1997) Stationary rossby-wave propagation in a baroclinic atmosphere. Q J R Meteorol Soc 123:919-928. doi:10.1002/qj.49712354007

Barrucand M, Rusticucci M, Vargas W (2008) Temperature extremes in the south of South America in relation to Atlantic Ocean surface temperature and Southern Hemisphere circulation. J Geophys Res Atmos 113:D20111. doi:10.1029/2007JD009026

Berbery EH, Nogués-Paegle J (1993) Intraseasonal interactions between the Tropics and extratropics in the Southern Hemisphere. J Atmos Sci 50:1950-1965. doi:10.1175/15200469(1993)050<1950:IIBTTA > 2.0.CO;2

Berman AL, Silvestri G, Compagnucci R (2012) Eastern Patagonia seasonal precipitation: influence of southern hemisphere circulation and links with subtropical South American precipitation. J Clim 25:6781-6795. doi:10.1175/JCLI-D-11-00514.1

Bretherton CS, Widmann M, Dymnikov VP et al (1999) The effective number of spatial degrees of freedom of a time-varying field. J Clim 12:1990-2009. doi:10.1175/1520-0442(1999)012<1990: TENOSD $>2.0 . \mathrm{CO} ; 2$

Brönnimann S, Compo GP (2012) Ozone highs and associated flow features in the first half of the twentieth century in different data sets. Meteorol Zeitschrift 21:49-59. doi:10.1127/0941-2948/2012/0284

Brönnimann S, Luterbacher J, Staehelin J et al (2004) Extreme climate of the global troposphere and stratosphere in 1940-42 related to El Nino. Nature 431:971-974

Brönnimann S, Compo GP, Spadin R et al (2011) Early ship-based upper-air data and comparison with the twentieth century reanalysis. Clim Past 7:265-276. doi:10.5194/cp-7-265-2011

Cai W, Whetton PH, Pittock AB (2001) Fluctuations of the relationship between ENSO and northeast Australian rainfall. Clim Dyn 17:421-432. doi:10.1007/PL00013738

Cai W, van Rensch P, Cowan T, Sullivan A (2010) Asymmetry in ENSO teleconnection with regional rainfall, its multidecadal variability, and impact. J Clim 23:4944-4955. doi:10.1175/ 2010JCLI3501.1

Carvalho LMV, Jones C, Silva AE et al (2011) The South American monsoon system and the 1970s climate transition. Int J Climatol 31:1248-1256. doi:10.1002/joc. 2147

Cerne SB, Vera CS (2011) Influence of the intraseasonal variability on heat waves in subtropical South America. Clim Dyn 36:2265-2277. doi:10.1007/s00382-010-0812-4 
Compo GP, Whitaker JS, Sardeshmukh PD et al (2011) The twentieth century reanalysis project. Q J R Meteorol Soc 137:1-28. doi:10. $1002 /$ qj. 776

Crowley TJ (2000) Causes of climate change over the past 1000 years. Sci 289:270-277. doi:10.1126/science.289.5477.270

Díaz A, Aceituno P (2003) Atmospheric circulation anomalies during episodes of enhanced and reduced convective cloudiness over Uruguay. J Clim 16:3171-3185. doi:10.1175/15200442(2003)016<3171:ACADEO > 2.0.CO;2

Doyle ME, Barros VR (2002) Midsummer low-level circulation and precipitation in subtropical South America and related sea surface temperature anomalies in the South Atlantic. J Clim 15:3394-3410. doi:10.1175/1520-0442(2002)015<3394: MLLCAP $>2.0 . C O ; 2$

Ebisuzaki W (1997) A method to estimate the statistical significance of a correlation when the data are serially correlated. J Clim 10:2147-2153. AMTETS $>2.0 . \mathrm{CO} ; 2$

Falvey M, Garreaud RD (2009) Regional cooling in a warming world: recent temperature trends in the southeast Pacific and along the west coast of subtropical South America (1979-2006). J Geophys Res Atmos 114:D04102. doi:10.1029/2008JD010519

Fogt RL, Bromwich DH (2006) Decadal variability of the ENSO teleconnection to the high-latitude South Pacific governed by coupling with the Southern Annular Mode*. J Clim 19:979-997. doi:10.1175/JCLI3671.1

Fogt R, Bromwich D, Hines K (2011) Understanding the SAM influence on the South Pacific ENSO teleconnection. Clim Dyn 36:1555-1576. doi:10.1007/s00382-010-0905-0

Gallego D, Ribera P, Garcia-Herrera R et al (2005) A new look for the Southern Hemisphere jet stream. Clim Dyn 24:607-621. doi:10. 1007/s00382-005-0006-7

Garreaud R (2000) Cold air incursions over subtropical South America: mean structure and dynamics. Mon Weather Rev 128:2544-2559. doi:10.1175/1520-0493(2000)128<2544: CAIOSS $>2.0 . \mathrm{CO} ; 2$

Garreaud R, Wallace JM (1998) Summertime incursions of midlatitude air into subtropical and tropical South America. Mon Weather Rev 126:2713-2733. doi:10.1175/15200493(1998)126<2713:SIOMAI >2.0.CO;2

Garreaud RD, Vuille M, Compagnucci R, Marengo J (2008) Presentday south american climate. Palaeogeogr Palaeoclimatol Palaeoecol. doi:10.1016/j.palaeo.2007.10.032

Garreaud RD, Vuille M, Compagnucci R, Marengo J (2009) Presentday south american climate. Palaeogeogr Palaeoclimatol Palaeoecol 281:180-195. doi:10.1016/j.palaeo.2007.10.032

Garreaud R, Lopez P, Minvielle M, Rojas M (2012) Large-scale control on the Patagonian climate. J Clim 26:215-230. doi:10. 1175/JCLI-D-12-00001.1

Gershunov A, Schneider N, Barnett T (2001) Low-frequency modulation of the ENSO-Indian monsoon rainfall relationship: signal or noise? J Clim 14:2486-2492. doi:10.1175/15200442(2001)014<2486:LFMOTE $>2.0$. CO;2

Gillett NP, Kell TD, Jones PD (2006) Regional climate impacts of the Southern Annular Mode. Geophys Res Lett 33:1-4. doi:10.1029/ 2006GL027721

Grimm AM, Zilli MT (2009) Interannual variability and seasonal evolution of summer monsoon rainfall in South America. J Clim 22:2257-2275. doi:10.1175/2008JCLI2345.1

Hendon HH, Thompson DWJ, Wheeler MC (2007) Australian rainfall and surface temperature variations associated with the Southern Hemisphere annular mode. J Clim 20:2452-2467. doi:10.1175/ JCLI4134.1

Jacques M (2009) Caracterización del salto climático de mediados de los 1970s en Sudamérica. MSc Thesis. Universidad de Chile
Jones PD, Osborn TJ, Briffa KR (1997) Estimating sampling errors in large-scale temperature averages. J Clim 10:2548-2568. doi:10. 1175/1520-0442(1997)010<2548:ESEILS > 2.0.CO;2

Kerr RA (1992) Unmasking a shifty climate system. Science 255(80):1508-1510. doi:10.1126/science.255.5051.1508

Kidson JW (1991) Intraseasonal variations in the Southern Hemisphere circulation. J Clim 4:939-953. doi:10.1175/15200442(1991)004<0939:IVITSH > 2.0.CO;2

L'Heureux ML, Thompson DWJ (2006) Observed relationships between the El Niño-Southern Oscillation and the extratropical zonal-mean circulation. J Clim 19:276-287. doi:10.1175/ JCLI3617.1

Legates DR, Willmott CJ (1990a) Mean seasonal and spatial variability in gauge-corrected, global precipitation. Int J Climatol 10:111-127. doi:10.1002/joc.3370100202

Legates DR, Willmott CJ (1990b) Mean seasonal and spatial variability in gauge-corrected, global precipitation. Int J Climatol 10:111-127. doi:10.1002/joc.3370100202

Liebmann B, Mechoso CR (2011) The South American monsoon system. In: Chang C-P, Ding Y, Lau N-C (eds) The global monsoon system: research and forecast, 2nd edn. World Scientific Publication Company, Singapore, pp 137-157

Liebmann B, Kiladis GN, Marengo J et al (1999) Submonthly convective variability over South America and the South Atlantic convergence zone. J Clim 12:1877-1891. doi:10.1175/ 1520-0442(1999)012<1877:SCVOSA $>2.0 . C O ; 2$

Liebmann B, Kiladis GN, Vera CS et al (2004) Subseasonal variations of rainfall in South America in the vicinity of the low-level jet east of the Andes and comparison to those in the South Atlantic convergence zone. J Clim 17:3829-3842. doi:10.1175/15200442(2004)017<3829:SVORIS>2.0.CO;2

Luterbacher J, Neukom R, González-Rouco F et al (2011) Reconstructed and simulated medieval climate anomaly in southern South America. PAGES news 19:20-21

Mantua NJ, Hare SR, Zhang Y et al (1997) A Pacific interdecadal climate oscillation with impacts on salmon production. Bull Am Meteorol Soc 78:1069-1079. doi:10.1175/15200477(1997)078<1069:APICOW>2.0.CO;2

Marengo JA, Soares WR, Saulo C, Nicolini M (2004) Climatology of the low-level jet east of the Andes as derived from the NCEPNCAR reanalyses: characteristics and temporal variability. J Clim 17:2261-2280. doi:10.1175/1520-0442(2004)017<2261: COTLJE $>2.0 . \mathrm{CO} ; 2$

Marshall GJ (2003) Trends in the Southern Annular Mode from observations and reanalyses. J Clim 16:4134-4143. doi:10.1175/ 1520-0442(2003)016<4134:TITSAM $>2.0 . \mathrm{CO} ; 2$

Meehl GA et al (2007) Global climate projections. In: Solomon S (ed) Climate change 2007: the physical science basis. Cambridge University press, Cambridge, pp 747-846

Mo KC, Paegle JN (2001) The Pacific-South American modes and their downstream effects. Int J Climatol 21:1211-1229. doi:10. 1002/joc. 685

Montecinos A, Purca S, Pizarro O (2003) Interannual-to-interdecadal sea surface temperature variability along the western coast of South America. Geophys Res Lett 30:1570. doi:10.1029/ 2003GL017345

Neukom R, Luterbacher J, Villalba R et al (2010) Multi-centennial summer and winter precipitation variability in southern South America. Geophys Res 37:1-6. doi:10.1029/2010GL043680

Neukom R, Luterbacher J, Villalba R et al (2011) Multiproxy summer and winter surface air temperature field reconstructions for southern South America covering the past centuries. Clim Dyn 37:35-51. doi:10.1007/s00382-010-0793-3

Nogués-Paegle J, Mo KC (1997) Alternating wet and dry conditions over South America during summer. Mon Weather Rev 
125:279-291. doi:10.1175/1520-0493(1997)125<0279:AWAD $\mathrm{CO}>2.0 . \mathrm{CO} ; 2$

Peterson TC, Vose RS (1997) An overview of the global historical climatology network temperature database. Bull Am Meteorol Soc 78:2837-2849. doi:10.1175/1520-0477(1997)078<2837: AOOTGH $>2.0 . \mathrm{CO} ; 2$

Piovano EL, Ariztegui D, Moreira SD (2002) Recent environmental changes in Laguna Mar Chiquita (central Argentina): a sedimentary model for a highly variable saline lake. Sedimentology 49:1371-1384. doi:10.1046/j.1365-3091.2002.00503.x

Power S, Casey T, Folland C et al (1999) Inter-decadal modulation of the impact of ENSO on Australia. Clim Dyn 15:319-324. doi:10. $1007 / \mathrm{s} 003820050284$

Power S, Haylock M, Colman R, Wang X (2006) The predictability of interdecadal changes in ENSO activity and ENSO teleconnections. J Clim 19:4755-4771. doi:10.1175/JCLI3868.1

Rayner NA, Parker DE, Horton EB et al (2003) Global analyses of sea surface temperature, sea ice, and night marine air temperature since the late nineteenth century. J Geophys Res Atmos 108:4407. doi:10.1029/2002JD002670

Rodionov SN (2005) A sequential method for detecting regime shifts in the mean and variance. In: Velikova V, Chipev N (eds) Largescale disturbances (regime shifts) recover. Aquat Ecosyst Challenges Manag Towar Sustain, Varna, pp 68-72

Rosenblüth B, Fuenzalida HA, Aceituno P (1997) Recent temperature variations in southern South America. Int J Climatol 17:67-85. doi:10.1002/(SICI)1097-0088(199701)17:1<67:AIDJOC120>3.0.CO;2-G

Röthlisberger M (2012) Vergleich des El Niño Signals in unterschiedlichen Datensätzen und anhand verschiedener El Niño Definitionen. BSc Thesis. Universität Bern

Sen Gupta A, England MH (2006) Coupled ocean-atmosphere-ice response to variations in the Southern Annular Mode. J Clim 19:4457-4486. doi:10.1175/JCLI3843.1
Silvestri GE, Vera CS (2003) Antarctic oscillation signal on precipitation anomalies over southeastern South America. Geophys Res Lett 30:2115. doi:10.1029/2003GL018277

Silvestri G, Vera C (2009) Nonstationary impacts of the southern annular mode on Southern Hemisphere climate. J Clim 22:6142-6148. doi:10.1175/2009JCLI3036.1

Smith TM, Reynolds RW (2004) Improved extended reconstruction of SST (1854-1997). J Clim 17:2466-2477. doi:10.1175/15200442(2004)017<2466:IEROS > 2.0.CO;2

Thompson DWJ, Solomon S (2002) Interpretation of recent southern hemisphere climate change. Sci 296:895-899. doi:10.1126/ science. 1069270

Trenberth KE (1990) Recent observed interdecadal climate changes in the Northern Hemisphere. Bull Am Meteorol Soc 71:988-993. doi:10.1175/1520-0477(1990)071<0988:ROICCI >2.0.CO;2

Trenberth KE et al (2007) Observations: surface and atmospheric climate change. In: Solomon S (ed) Climate change 2007: the physical science basis. Cambridge University Press, Cambridge, pp 253-336

Uppala SM, Kållberg PW, Simmons AJ et al (2005) The ERA-40 reanalysis. Q J R Meteorol Soc 131:2961-3012. doi:10.1256/qj.04.176

Wang G, Cai W (2013) Climate-change impact on the 20th-century relationship between the Southern Annular Mode and global mean temperature. Sci Rep 3. doi:10.1038/srep02039

Welker C, Martius O (2012) Variability of cyclones over the North Atlantic and Europe since 1871. Geophys Res Abstr 14:2507

Yeh S-W, Kug J-S, Dewitte B et al (2009) El Nino in a changing climate. Nature 461:511-514

Zhang Z-Y, Gong D-Y, He X-Z et al (2010) Statistical reconstruction of the antarctic oscillation index based on multiple proxies. Atmos Ocean Sci Lett 3:283-287

Zhang Q, Körnich H, Holmgren K (2012) How well do reanalyses represent the southern African precipitation? Clim Dyn 40:951-962. doi:10.1007/s00382-012-1423-Z 